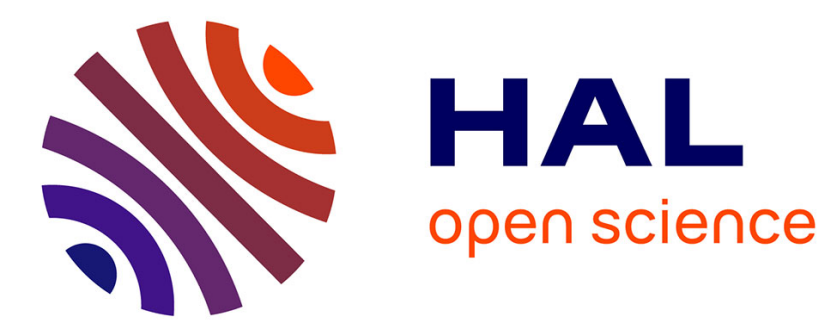

\title{
Réhabiliter le Funan. Óc Eo ou la première Angkor Éric Bourdonneau
}

\section{To cite this version:}

Éric Bourdonneau. Réhabiliter le Funan. Óc Eo ou la première Angkor. Bulletin de l'Ecole française d'Extrême-Orient, 2007, 94, pp.111-158. 10.3406/befeo.2007.6067 . halshs-01885994

\section{HAL Id: halshs-01885994 https://shs.hal.science/halshs-01885994}

Submitted on 10 Oct 2018

HAL is a multi-disciplinary open access archive for the deposit and dissemination of scientific research documents, whether they are published or not. The documents may come from teaching and research institutions in France or abroad, or from public or private research centers.
L'archive ouverte pluridisciplinaire HAL, est destinée au dépôt et à la diffusion de documents scientifiques de niveau recherche, publiés ou non, émanant des établissements d'enseignement et de recherche français ou étrangers, des laboratoires publics ou privés. 


\section{Réhabiliter le Funan. Óc Eo ou la première Angkor}

\section{Éric Bourdonneau}

\section{Citer ce document / Cite this document :}

Bourdonneau Éric. Réhabiliter le Funan. Óc Eo ou la première Angkor. In: Bulletin de l'Ecole française d'Extrême-Orient. Tome 94, 2007. pp. 111-158;

doi : https://doi.org/10.3406/befeo.2007.6067

https://www.persee.fr/doc/befeo_0336-1519_2007_num_94_1_6067

Fichier pdf généré le 08/05/2018 


\begin{abstract}
Éric Bourdonneau

"Rehabilitating Funan. Óc Eo, or, the first Angkor"

Funanese history is one of the main transitional periods in the history of Southeast Asia. This makes it very susceptible to the changing historiographical positions on the two great issues of Indianization and state-formation. For more than three decades, in reaction to previous studies, the new priority has been to demonstrate how these two processes had no real effect on the cultural and socio-political continuity of the history of the region. Because Funanese history had earlier been taken to illustrate the close connection between Indianization and state-formation, it seemed imperative to review this history, given the perceived importance of the separation of these two processes.

The outcome of this new approach is a curious view of Funanese history deprived of its main documentary sources in order to fit the concept of an only superficially Indianized "proto-state". In that respect, the surprising omission of the "urbanism" of Óc Eo speaks for itself. The purpose of the present paper is to undertake afresh the description of this urbanism and to demonstrate again, thanks in part to newly available data, both its antiquity and the reference to an Indian model. That leads us to rethink the place of Óc Eo in the urban history of the region, and to consider it as a kind of "first Angkor" whose geometric "urbanism" is a major feature of ancient Cambodia.
\end{abstract}

\title{
Résumé
}

Éric Bourdonneau

"Réhabiliter le Funan. Óc Eo ou la première Angkor »

L'histoire funanaise occupe une position charnière dans l'histoire de l'Asie du Sud- Est. Cela l'a rendue extrêmement sensible à l'évolution des regards portés sur les deux grandes problématiques qui traversent l'historiographie : l'indianisation et la formation de l'État. Depuis trois bonnes décennies, en réaction aux travaux antérieurs, la priorité s'est imposée de montrer combien ces deux processus n'ont guère affecté la continuité culturelle et sociopolitique de la région. L'histoire du Funan apparaît d'autant plus sujette à révision qu'elle illustrait jusqu'alors l'étroite imbrication entre l'indianisation et la formation de l'État. De différentes façons, il importerait désormais de disjoindre ces deux processus.

Il en résulte cette image curieuse d'un Funan dépossédé de ses principales sources documentaires, afin de correspondre au mieux à la vision d'un " proto-État " qui ne serait indianisé que superficiellement. Emblématique à cet égard est le traitement réservé à l'« urbanisme » de l'ancienne ville de Óc Eo, dont les grandes caractéristiques font l'objet d'un « oubli » surprenant. Nous nous proposons ici d'en reprendre la description, puis de refaire la démonstration, à la lueur des nouvelles données disponibles, tant de son ancienneté que de la référence à un modèle indien. Ce faisant, nous sommes amené à repenser la place de Óc Eo dans l'histoire urbaine de la région, en la définissant comme une sorte de " première Angkor » dont l'« urbanisme " géométrique apparaît comme l'une des grandes spécificités du Cambodge ancien. 


\title{
Réhabiliter le Funan Óc Eo ou la première Angkor
}

\author{
Éric BOURDONNEAI; *
}

Cela résonne un peu étrangement d'appeler à une réhabilitation du Funan, tant il est vrai que celui-ci demeure un passage obligé de toute histoire ancienne de l'Asie du SudEst. A bien des égards, le Funan fait pourtant figure de mal-aimé de l'historiographie. À commencer par le nom par lequel on le désigne : périodiquement, les successeurs de George Cœedès ont appelé à rompre avec l'usage même du terme Funan, supposé véhiculer la vision biaisée de l'histoire locale transmise par les anciens auteurs chinois '.

Le paradoxe tient peut-être à la position que le Funan occupe à la marge d'objets historiques plus aisément définissables. La connaissance acquise à son sujet s'est ainsi construite à la périphérie de domaines qui ont suscité davantage de travaux : le Cambodge préangkorien du Zhenla, contemporain et légèrement postérieur, la protohistoire thaïlandaise, contemporaine et légèrement antérieure, ou encore l'émergence des premiers États côtiers de la péninsule Thaï-Malaise et de l'archipel indonésien (Wisseman Christie 1995). Entre Asie du Sud-Est maritime et continentale, histoire et préhistoire, sources écrites et archéologiques, la référence au Funan est omniprésente dans la recherche asiatique mais la connaissance de son histoire n'a pas toujours bénéficié de cette position charnière et demeure écartelée entre les différents domaines d'étude.

Cette position paradoxale de l'histoire du Funan s'explique aussi, et de façon sans doute plus fondamentale, par l'évolution du regard porté par l'historiographie sur les grands processus qui ont marqué les débuts de l'histoire sud-est asiatique. Le maîtremot est désormais la continuité. S'il est des changements constatés, ils seraient surtout le fait de processus d'intensification. Continuité économique : le principal ressort de la croissance des chefferies protohistoriques puis des «premiers États » demeurerait le commerce; le Funan ne ferait ici que bénéficier d'une intensification croissante des liens commerciaux tissés aux époques antérieures avec la Chine et le sous-continent indien. Continuité culturelle : l'indianisation ne jouerait, au mieux, qu'un rôle secondaire dans la dynamique culturelle de la région, les emprunts faits à l'Inde étant le produit d'une sélection en accord avec le substrat local. Continuité sociale et politique : au sein des premiers États comme des chefferies qui les ont précédés, la capitalisation de « l'honneur social » par les élites locales qui s'emparent des biens de prestige issus du commerce hauturier et de la référence indienne (à laquelle on reconnaît une certaine efficacité en terme de légitimité) offrirait un caractère précaire, provisoire, toujours susceptible d'être remis en cause par de nouveaux « hommes de prouesse ».

\footnotetext{
* Maître de conférences à l'École française d’Extrême-Orient.
}

1. Sur cette question, voir Bourdonneau 2003 a. 
L'histoire funanaise apparaît comme l'une des principales victimes de cette nouvelle vision des choses car, dans les premiers travaux qui lui furent consacrés, elle incarne tout ce qu'il s'agit désormais de relativiser. Le Funan, qui représentait jusqu'alors le premier État de la région, est à présent réinterprété comme une nébuleuse amorphe de cités portuaires, dépourvue des critères supposés caractériscr le véritable État; lui qui paraissait livrer les témoignages les plus probants d'une indianisation, est désormais surtout cité pour montrer combien cette indianisation est en réalité tardive et superficielle. L'histoire funanaise devient d'autant plus sujette à révision qu'elle illustrait également l'étroite imbrication entre les deux processus qu'il paraît désormais impératif de disjoindre : si l'utilisation, prudente, des notions d'État et d'indianisation peut, à la rigueur, être admise, il serait en revanche exclu de combiner l'une et l'autre. Ce serait aussitôt laisser entendre que l'indianisation fut une condition nécessaire à la formation de l'État et que, sans l'Inde, l'Asie du Sud-Est n'aurait pu sortir seule de la préhistoire. En d'autres termes, ce serait se faire l'écho des anciennes thèses marquées par le contexte colonial qui les a vues naître.

De façon plus ou moins consciente, cette nouvelle tendance de l'historiographie se traduit par la volonté d'attribuer à une époque antérieure et surtout postérieure au Funan les témoignages soit d'une indianisation, soit de l'existence de l'État: d'une façon ou d'une autre, l'histoire funanaise ne doit pas apparaître comme le lieu de leur conjonction. Une démarche du même ordre consiste à expliquer par la venue de marchands du sous-continent la présence de documents "indianisés » dont la contemporanéité avec le Funan pouvait être difficilement contestée 2 . Dans chacun des cas, on obtient cette image curieuse d'un Funan dépossédé de ses principales sources documentaires, afin de correspondre au mieux à la vision d'un «proto-État » marchand qui ne serait indianisé que de façon superficielle ${ }^{3}$.

Rendre au Funan ce qui appartient au Funan. Tel sera donc en somme notre propos, en montrant qu'il n'y a là aucun retour aux anciennes thèses " indo-centriques ». Notre étude comportera trois volets distincts qui nous permettront d'illustrer à partir de sources différentes la « réhabilitation » que nous appelons ici de nos vœux. Le présent article est consacré au tracé géométrique de l'un des sites les plus fameux du Funan, Óc Eo, tracé pour lequel les fouilles récentes de la mission "Archéologie du delta du Mékong » ont permis d'obtenir une série de datations $\mathrm{C}^{14(4)}$. Un second volet, épigraphique, portera sur l'étude d'une inscription sanskrite, K. 1142, mal comprise à ce jour, qui comprend la plus longue généalogie royale de l'époque préangkorienne (Ishizawa el al. 2007 : 47). Celle-ci nous fait connaître le plus ancien roi (non légendaire) du Funan, et par la même occasion du Cambodge, mentionné dans les inscriptions : Candravarman. Enfin,

2. Nous verrons que c'est en particulier le cas des sceaux retrouvés à Óc Eo.

3. Le récent article de Michael Vickery " Funan Reviewed: Deconstructing the Ancients » (2003-04) ne fait pas exception. L'objectif affiché par l'auteur est une critique de la " synthèse standard " de l’histoire funanaise telle qu'elle a été formulée par George Coedès. La " déconstruction " proposée consiste surtout à prendre l'exact contrepoint de l'opinion des « anciens " visés par l'auteur et apparaît, au final, bien peu (dé)constructionniste (ef. Bourdonneau 2003a). Par ailleurs, il est assè discutable de présenter le travail de Coedes comme la "synthèse standard" en matière d'histoire funanaise. quand la littérature répète depuis un bon quart de siècle combien les analyses de celui-ci seraient datées.

4. La mission " Archéologe du delta du Mékong " est une collaboration établie entre l ĺcole française d’Extrême-Orient et l'Institut des sciences sociales de Hô ('hi Minh-Ville, sous la direction de PierreYves Manguin, Vò Sì Khài et Đào Linh Côn. 
un troisième volet. relevant en partie de l'histoire de l'art. traitera de l'image en rondebosse d'un magnifique Viṣnu récemment «exhumé » des réserves du musée national de Phnom Penh (Porte 2003: 84). Elle doit nous permettre de défendre la thèse d'une chronologie haute et funanaise de la première statuaire khmère.

Si nous débutons cette étude par l'examen de l'"urbanisme » géométrique de Óc Eo, c'est qu'il est à plus d'un titre emblématique des zones d'ombre qui subsistent dans le traitement réservé au Funan ${ }^{5}$. Non pas que l'importance de la ville de Óc Eo en elle-même ait été là encore ignorée. Óc Eo demeure certainement le site du Funan le plus célèbre et sa notoriété s'étend bien en dehors des seules études sur l'histoire sud-est asiatique. Cependant. il nous livre un exemple typique des récents efforts pour relativiser l'ancienneté et nier le caractère indianisé des sources de l'histoire funanaise. Nous verrons ici, en particulier, comment la thèse commerciale adoptée par l'historiographie a fortement contribué à interpréter ÓC Eo de cette façon : à ce point que les caractéristiques remarquables de l' « urbanisme » de la ville ont largement été passées sous silence. Reprendre la description de cet "urbanisme " est alors une première étape. Il s'agira ensuite de refaire la démonstration et de son ancienneté et de la référence à un modèle indien. Nous montrerons comment les données les plus récentes demeurent cohérentes avec les données connues de plus longue date. Nous nous efforcerons ensuite d'en tirer les conséquences qui s'imposent. Il importera ainsi de préciser de quelle façon l" " urbanisme " géométrique de Óc Eo apparaît comme une spécificité du Cambodge ancien. Nous serons alors amené à percevoir Óc Eo comme une sorte de « première Angkor » dont la place dans l'histoire du pays khmer doit être repensée.

\section{La thèse commerciale}

\section{Louis Malleret et les premières fouilles archéologiques : loin d'Angkor, un emporium}

Le site de Óc Eo se situe à la limite des actuelles provinces vietnamiennes de $\Lambda \mathrm{n}$ Giang et Kiên Giang, dans la partic occidentale du delta du Mékong ${ }^{\circ}$. On est ici à midistance entre le bras le plus occidental du fleuve et la côte du golfe du Siam, à proximité de l'éminence granitique du Ba Thê, la dernière d'une petite chaîne montagneuse qui court de part et d'autre de la frontière entre le Cambodge et le Vietnam (pl. 1). Faisant suite aux premiers travaux de Pierre Paris sur l'ancien réseau hydraulique de la région, qui attribuait déjà ce réseau au Funan, c'est aux vastes recherches de Louis Malleret que l'on doit la " découverte " scientifique de Óc Eo.

Celui-ci organisa, en 1944, une longue campagne de fouilles archéologiques sur le site. Ce dernier faisait alors depuis quelques années l'objet de fouilles sauvages qui alimentaient le marché des antiquaires de Saigon en bijoux en or. Après enquête et prospection dans un delta encore difficile d'accès, Malleret parvint à localiser la principale source d'approvisionnement des orpailleurs dans la plaine marécageuse qui s'étend au pied du Ba Thê. À partir de 1943, quelque 400 objets furent acquis auprès des orpailleurs clan-

5. Nous verrons plus loin pourquoi il nous semble nécessaire de placer le mot "urbanisme " entre guillemets.

6. Ancien “ trans-Bassac ». ke « Miền Tày » du Vam Bọ des Vietnamiens. 
destins opérant sur la surface de l'ancienne ville de Óc Eo. Les fouilles en elles mêmes, menées par Malleret, n'ont duré que deux mois à peine, début 1944, interrompues par l'insécurité et l'état de guerre.

Elles trouveront néanmoins un aboutissement dans la monumentale publication de L'archéologie du delta du Mékong. Précédé par divers articles, l'ouvrage intègre les recherches et les fouilles ponctuelles menées plus généralement par Malleret dans l'ensemble du delta du Mékong à partir de 1938. Paru en 4 tomes et 7 volumes entre 1959 et 1963, il reste néanmoins pour une très large part consacré aux vestiges de Óc Eo.

Cette publication eut un grand retentissement dans le monde des chercheurs. Elle révélait une importante activité dans une région qu'on supposait jusque-là dépourvue de tout vestige. Mais elle fit surtout connaître un matériel archéologique que l'on ne s'attendait pas alors à rencontrer en Asie du Sud-Est. Le commentaire que fit, plus tard, Bernard Philippe Groslier des découvertes de Malleret donne une assez bonne idée de l'enthousiasme qu'elles ont pu susciter : «outre les vestiges d'une culture indigène développée, [Malleret] exhuma une série de pièces indiennes - des bijoux surtout - méditerranéennes - médaillon d'Antonin le pieux, intailles, cabochons, etc. - et chinoises. Malgré l'absence de méthode archéologique [...] on put, pour la première fois, toucher du doigt les plus anciens témoins concrets du commerce indien $-{ }_{11^{\mathrm{C}}-\mathrm{III}}^{\mathrm{e}} \mathrm{s}$. - et les pacotilles méditerranéennes que celui-ci avait charriées. Nous disposons désormais du point d'arrivée (au moins du plus ancien connu) de la route dont Wheeler avait découvert le point de départ (du moins à l'époque de la Rome impériale) » (Groslier $1985: 255$ ).

Plus récemment, Jean Boisselier s'est efforcé de tempérer cet enthousiasme, reprochant à Malleret d'avoir proposé une vision biaisée de l'archéologie du delta du Mékong. Le « découvreur » de Óc Eo aurait été « obnubilé à la fois par la découverte de médailles et d'intailles romaines ou hellénistiques, par les échos de l'ambassade de Marc-Aurèle en Chine (en 166 A. D.) et par l'intérêt suscité par la géographie de Ptolémée " (Boisselier $1992: 281$ ). Le commentaire de Boisselier est pris dans une démonstration dont les présupposés sont eux-mêmes très discutables ( $\mathrm{cf}$. infira) et rend peu justice à une étude qui, en dépit de ses lacunes méthodologiques, se distingue par le soin apporté à la publication systématique des données disponibles. Il reste vrai que l'ouvrage de Malleret esquisse une vision de l'histoire funanaise profondément marquée par les témoignages d'échanges entre le delta du Mékong et des régions plus ou moins lointaines. Et l'on conviendra avec Boisselier que les longues spéculations auxquelles se livre Malleret pour tenter d'assigner une place à Óc Eo dans la géographie de Ptolémée sont quelque peu à l'image de la tonalité dominante de son Archéologie du delta du Mékong. Cette orientation va perdurer bien au-delà de l'étude de Louis Malleret. Elle composa désormais le versant archéologique de la thèse du Funan comme «État » ou «proto-État» marchand dont le commerce maritime hauturier aurait été le principal moteur de l'histoire.

\section{Bipolarité et rythme ternaire de l'histoire khmère et sud-est asiatique}

Cette vision du Funan est venue directement alimenter un schéma bipolaire appliqué à l'ensemble de l'histoire du Cambodge et de l'Asie du Sud-Lst. Les grandes lignes de ce schéma sont connues : à une façade maritime, "multipolaire ", formée d'une chaîne de sites portuaires à vocation commerciale, au nombre desquels il faudrait compter ceux du Funan, s’opposerait un arrière-pays agraire, davantage centralisé politiquement (mais 
sans être toujours clairement unifié). représenté par les grands États contemporains de l'édification des complexes monumentaux d’Angkor. de Pagan ou de Java-central.

Les travaux de Bernard Philippe Groslier et de Denys Lombard, respectivement sur le pays khmer et sur Java, figurent parmi les applications les plus fameuses et les plus abouties de cette proposition de lecture sur le «temps long » de l'histoire sud-est asiatique.

Dans sa "géographie historique du Cambodge ". Groslier propose de diviser celui-ci en deux triangles opposés par leur sommet, ce dernier placé au cœur du Cambodge actuel (Phnom Penh). Le premier triangle correspondrait en partie au delta du Mékong et s'étendrait entre le cours du Bassac, les Cardamomes et la mer. C'est là, rappelle Groslier (1973:340), grosso modo la zone d'extension de l'État funanais. Le second Cambodge se développerait au nord. délimité à la fois par le Tonle Sap et le Moyen Mékong et débordant sur le plateau de Korat. Il correspond bien sûr au cour historique du Cambodge de la période angkorienne. Pour l'époque postangkorienne, Groslier suggère de reconnaître un retour aux formules funanaises, lorsque les Khmers, à partir du $X V I^{\circ}$ siècle, commencent de refluer vers les Quatre-Bras. I a réapparition du facteur maritime dans l'histoire khmère s'expliquerait par les mêmes conditions que celles qui auraient suscité le Funan, le rôle de ce dernier étant comparé à celui joué désormais par le Siam dans le grand commerce des épices « cette fois aux mains des Européens et non plus des Indiens (quoique via l'Inde et Ceylan) » (ihid., p. 353-354).

L'opposition entre centre agraire et côte marchande est un thème également largement développé dans le Carrefour javanais de Denys Lombard. Proposant une image d'ensemble de la région vue depuis Java, l'auteur distingue, rappelons-le, trois grandes "nébuleuses socio-culturelles": celle. la plus récente, marquée par l'occidentalisation: celle formée au contact de l'islam et de la Chine, dans les ports commerçants qui ont $\mathrm{vu}$ le jour à partir du $\mathrm{Xv}^{\mathrm{N}}$ siècle; celle enfin des anciens royaumes agraires indianisés (Lombard 1990. vol. I : 9). Entre la première et la deuxième «strate », il n'existe pas, note l'auteur, de réelle discontinuité : « dans le cas des cellules occidentalisées, comme dans celui des réseaux asiatiques, il s"est agi chaque fois de sociétés ouvertes aux vents du large et entées sur un faisceau de cités portuaires à peu de choses près identiques. Ce qui nous a conduit à les distinguer c'est avant tout la prégnance du fait colonial » (1990, vol. III : 152). Fondée sur les étendues rizicoles de l'intérieur, la troisième " nébuleuse " définie par l'auteur contraste en revanche nettement avec les deux précédentes. Si bien que la distinction en trois "strates" se ramène à un antagonisme fondamental entre espaces agraires et monde des réseaux dans lequel Lombard voit un des ressorts essentiels de l'histoire de Java et plus généralement de l'Indonésie.

Dans ses «ultimes réflexions » sur les vertus du cas javanais, Lombard attirait l'attention sur la possibilité d'une quatrième «nébuleuse », protohistorique celle-là, qui correspondrait au temps des sociétés pré- ou proto-étatiques, antérieures à l'avènement des grands royaumes concentriques indianisés. Cette "nébuleuse » est progressivement documentée grâce aux progrès de l'archéologie de fouilles de ces trente dernic̀rcs années. Or, comme nous l'avons déjà souligné, la tendance dominante parmi ces travaux d'archéologie protohistorique a été d'interpréter les témoignages de cette "nébuleuse " comme ceux d'un premier " monde des réseaux », précurseur en un sens de celui du grand boom commercial du second millénaire. Une telle interprétation a été largement étendue, par les mêmes auteurs, à l’étude des formations politiques des premiers siècles de notre ère. 
parmi lesquelles celle du Funan. On retrouverait ainsi, pour l'Asie du Sud-Est maritime, sensiblement le même mouvement de l'histoire que celui esquissé par Groslier pour le Cambodge. La périodisation en trois temps s'imposerait comme l'effet d'une sorte de mouvement de balancier entre les deux pôles définis, le monde des réseaux et celui des royaumes concentriques de l'intérieur.

Cette lecture structurelle de l'histoire sud-est asiatique fait néanmoins difficulté sur plusieurs points. Le rythme ternaire et la géographie ou l'économie bipolaire supposée lui correspondre sont loin d'avoir les contours impeccables qu'une telle vision esquissée à grands traits laisse supposer. Les historiens modernistes ont sensiblement nuancé ces dernières années la vision d'une Asie du Sud-Est dominée par le " monde des réseaux » dans le milieu du second millénaire. La thèse fameuse d'Anthony Reid (1988 et 1993), définissant cette période comme "l'âge du commerce " de l'histoire sud-est asiatique, et qui emboîtait le pas à certaines observations de Lombard, a progressivement fait l'objet de différentes critiques. On lui a ainsi reproché de proposer une vision déséquilibrée de l'histoire de la région, manquant de rendre compte des dynamiques spécifiques à l'Asie du Sud-Est continentale? . Pour une période antérieure, celle supposée des « royaumes agraires ", une telle vision a conduit à occulter le «boom commercial » du tournant du premier millénaire et le rôle que l'île de Java y a tenu ${ }^{8}$. Une telle périodisation intègre également assez mal l'histoire commerciale et maritime du royaume sumatranais de Śrīvijaya.

De façon inverse, pour les périodes encore plus anciennes, correspondant à la formation des premiers États, cette lecture structurelle a conduit à dresser imprudemment une sorte de parallèle entre des processus très éloignés dans le temps. De la même façon que la moitié du second millénaire a vu l'affirmation des États modernes de la région à l'heure du grand "âge du commerce ", l'émergence des premières chefferies et «proto-États » au tournant de notre ère (englobant plus ou moins largement les premiers siècles avant et après J.-C.) aurait été largement suscitée par un premier «boom » du commerce hauturier sud-est asiatique avec les mondes chinois, indien ou méditerranéen (Wisseman Christie 1995). On reconnaît ici la thèse commerciale telle qu'elle a été appliquée à l'histoire funanaise. Elle est en partie le produit d'une archéologie protohistorique, émergeante sur la région, prompte à restituer l'existence de réseaux marchands dès la plus haute époque.

Ce n'est pas le lieu de procéder à une pleine contre-argumentation de cette thèse (ou de la forme qu'elle prend lorsqu'elle glisse vers une théorie des "biens de prestige ») qui demeure, à nos yeux, problématique". Relevons simplement qu'elle offre, dans l'historiographie récente, le pendant "nécessaire » de la thèse de la "localization" telle qu'elle a été formulée par Oliver Wolters (1999) et largement adoptée, nous l'avons vu en introduction, par l'historiographie récente. Reprochant aux travaux plus anciens de ne reconnaître d'initiative que venant de l'Inde ou de la Chine, la thèse de Wolters vise à mettre autant que possible l'accent sur le rôle des sociétés sud-est asiatiques dans l'écriture de leur histoire. On ne fait plus l'hypothèse de sociétés recevant passivement

7. Voir à ce sujet les remarcues de Victor L.ieberman (20)3).

8. Voir à ce propos les travaux récents de Jan Wisseman C'hristic (1998, 1999).

9. Nous avons proposé une première version de cette contre-argumentation dans une thèse de doctorat de Paris I, soutenue en 2005 (intitulée Indianisation et formation de / État en Asie chu Sud-Est : retoul

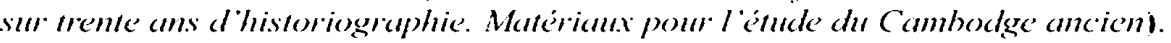


les apports culturels d'une Inde civilisatrice. mais celle de sociétés réinterprétant ces apports de telle sorte qu'ils " fassent sens » localement. Comme le revendique Wolters, cela consiste en l'adoption d'une approche " continuiste " faisant l'hypothèse de sociétés qui, en dernière analyse, restent culturellement et socialement identiques à elles-mêmes (ibid., p. 27, 51). Mais puisqu'il faut à la fois rendre compte de changements évidents, c'est à la thèse commerciale qu'il revient alors de les expliquer. Qu'il s'agisse de la formation des États ou proto-États au début de notre ère ou au milieu du second millénaire. toute évolution majeure dans l'histoire de la région tend à être attribuée à l'impact économique des grands réseaux d'échanges amenés à la traverser. À la périphérie ou entre deux moments d'ouverture au monde des réseaux, l'émergence de royaumes agraires est bien interprétée comme le signe d'une dynamique locale, mais il s'agit là d'un processus qui vient toujours en second et qui reste fondamentalement formulé comme la résurgence d'un « substrat " anhistorique.

La thèse commerciale et la thèse de la "localization" sont ainsi complémentaires au sein de l'historiographie «autonomiste» de ces trente dernières années: l'une vise à étayer l'hypothèse de la continuité tandis que l'autre prend en charge l'explication du changement mais sans reconnaître de réelle dynamique sociale et culturelle aux sociétés étudiées. Le risque est alors de reproduire implicitement le postulat d'une inertie locale que les deux thèses entendaient dénoncer chez les premiers auteurs ${ }^{10}$.

\section{"Ville marchande" versus "ville agraire".}

Óc Eo, paradigme ou contre-exemple?

Si le schéma bipolaire précédent s'est en partie nourri des observations de Malleret sur Óc Eo, il a en retour influencé considérablement l'interprétation du site en lui assignant une place quelque peu contraignante dans une typologie envisagée au plan strictement urbain.

Dans la démarche de Lombard, à chaque «nébuleuse culturelle » du carrefour javanais correspond une phase différente de l'histoire urbaine de la région. L'auteur s'est dit à plusieurs reprises frappé par le contraste entre deux grands types de villes sud-est asiatiques : la "ville agraire " et la "ville marchande " (Lombard 1970 et 1994). Ce contraste se signale de différentes façons. Dans la localisation des villes tout d'abord : comme on s'y attend, à l'implantation dans l'intérieur des terres des "villes agraires » va s'opposer la situation littorale des "villes marchandes ", en bordure de détroits ou à l'embouchure d'un fleuve. Les unes sont au cour de plaines rizicoles, les autres s'organisent en une chaîne de cités-États portuaires cosmopolites contrôlant les voies de circulation maritime et les biens et les hommes que celles-ci charrient. Ce contraste se signalerait de façon spectaculaire dans le plan respectif de ces villes. À un premier pôle représenté par la planification à la fois géométrique et cosmologique des grandes cités angkoriennes s'opposerait un second pôle se manifestant dans le « laisser-faire »des villes marchandes des sultanats indonésiens ". Comme Reid l'a rappelé plus récemment, cette distinction entre deux " urbanismes » fait écho aux remarques de Fernand Braudel sur la dichotomie entre les « cités en échiquiers » de l'Asie orientale

10. ('f. nos remarques dans Bourdonncau 2003a ou celles dans Lieberman 2003: 13. 19 (distinguant entre historiographies « externalist » et « antonomist»). Voir également Pollock $2007: 530-536$.

11. L.ombard 1994: 100. Voir aussi Reid 1980. 
et méridionale et le "désordre congestionné » des cités de l'Europe médiévale et de l'Islam « de Gibraltar aux îles de la Sonde » ${ }^{12}$.

Lombard et, à sa suite, Reid n'ont pas manqué d'apporter certaines nuances à une telle opposition, qu'ils ne voulaient pas formuler de façon trop tranchée (Lombard 1990, vol. IIl : 155). Aucune « ville agraire » ne vit sans commerce, de la même façon qu'aucune « ville marchande » ne vit sans importer les denrées nécessaires à son alimentation. Toutes les cités eurent également un certain degré d'ordre cosmique en leur cœur, quand bien même elles n'affichaient pas de plan en damier. Il en va ainsi généralement des villes de l'archipel, où seuls le palais royal et les bâtiments publics adjacents obéissaient à un projet de planification; les établissements aux alentours se distribuaient de façon plus irrégulière autour des marchés, des voies d'eau et des compounds de l'aristocratie (Reid 1993 : 77-78). Enfin, et surtout, il existe de nombreux exemples datés du second millénaire qui obligent à infléchir sensiblement le schéma d'un rythme ternaire. Lombard cite les villes de Kartasura, Yogyakarta et Surakarta à Java-central et surtout les capitales des royaumes bouddhiques birmans : Ava, Amarapura et Mandalay. Ces cités murées du Moyen-Irawadi, auxquelles on peut comparer les réalisations du Nord de la Thaïlande (Chiang Mai en tête), offrent certainement, dans l'histoire de l'urbanisme sud-est asiatique, les exemples les plus rigoureux de plan régulier étendu à l'ensemble de l'espace urbain. Lombard évoque à leur sujet la « permanence tardive » ou la « survivance » du modèle agraire dans les « régions intérieures » de l'Asie du Sud-Est. La formulation trahit le souci évident de préserver le caractère opérationnel d'un modèle, en dépit des nombreuses nuances à lui apporter. Tout en observant qu'il n'y eut pas d'opposition tranchée mais une concomitance entre les deux systèmes, l'auteur maintient que le contraste entre « villes agraires » et "villes marchandes » demeure, à ses yeux, l'un des ressorts essentiels de l'histoire de la région.

L'hypothèse en elle-même est sans doute peu contestable mais elle conduit, là encore, à ignorer ou à infléchir sensiblement certaines données disponibles. C'est au moins le cas s'agissant de Óc Eo. Dans ses «nouvelles considérations » sur la ville sud-est asiatique, Lombard se fait en ces termes l'écho de l'opinion partagée alors par les archéologues : "Les premiers sites [que les recherches archéologiques] ont permis de repérer çà et là apparaissent surtout, dans la mesure où l'on peut les interpréter, comme des "comptoirs", i.e. comme des haltes, sur une route maritime ancienne. Il ne fait aucun doute que c'est une route maritime en rapport avec la Chine et l'Inde, le Moyen-Orient (et parfois même la Méditerranée...) que l'on retrouve à l'origine d'Oc-éo, de Satingpra ou de Sriwijaya " (Lombard 1994: 102). Depuis les travaux de Malleret, on le voit, l'opinion n'a guère changé : Óc Eo scrait le port de commerce de l'État marchand du Funan. À ce titre, le site doit s'intégrer naturellement dans la classification des villes sud-est asiatiques, aux côtés des autres "cités marchandes" de l'histoire de la région. C'est omettre une dimension remarquable de la ville de Óc Eo : son plan " en damier » semblable à celui que Lombard associe étroitement à l'urbanisme des «villes agraires » (pl. 2-3).

Cette omission n'est pas une simple négligence de la part de Lombard, plus préoccupé de lecture sur le temps long et pour qui le Funan n'est ni la période ni la région

12. Reid 1993: 77 et Braudel 1973:385-395. Voir aussi Fox 1971 et Redfield \& Singer 1954. pour des typologies dualistes assez. semblables et mises récemment en application, pour l’archéologie sud-est asiatique, par John Miksic (Miksic 2000). 
de prédilection. Un tel «oubli» se retrouve également. et même surtout"; che $\%$ les auteurs dont les travaux traitent en priorité du Cambodge ancien (et des débuts de son histoire). À commencer par George Coedès : aucune mention n'est faite dans les États. hindouisés du plan géométrique de Óc Eo, défini comme « un emporium où étaient établis des commerçants étrangers ${ }^{14}$. La remarque vaut encore pour les articles et ouvrages de Claude Jacques et Michael Vickery portant, entièrement ou en partie. sur l'histoire du Funan ${ }^{15}$. De façon asse $z$ surprenante, le même «oubli » se retrouve encore che $\%$ Bernard Philippe Groslier tandis que celui-ci passe en revue les enceintes quadrangulaires du Cambodge préangkorien : Banteay Chhou (ou "ville sous baray" ") ", présenté comme le plus important ouvrage connu avant les premières réalisations angkoriennes, est cité aux côtés de Sambor Prei Kuk (" la première grande capitale khmère ») et de Wat Luong Kau. mais pas un mot n’est dit sur le plan de Óc Eo.

Le tracé géométrique de la ville de Óc Eo bouscule les grilles de lecture et contrarie aujourd'hui, encore plus que par le passé, les thèses admises sur les grands processus qui animent les premiers siècles de l'histoire sud-est asiatique. D'un côté, le concept d'indianisation est disqualifié au profit de l'hypothèse " continuiste » revendiquée notamment par Wolters: de l'autre. la thèse commerciale, en mettant l'accent sur l'initiative des marchands et non plus sur celle des lettrés indiens, est supposée rendre compte de la formation des premiers États ou proto-États au début de notre ère. Aux yeux de l'une et l'autre thèse, dont nous avons vu qu'elles étaient complémentaires, la ville de Óc Eo se définit beaucoup plus aisément comme un port de commerce, lieu important de passage des biens et des hommes, mais qui, pour cette raison, ne permettait guère aux influences culturelles de s'ancrer profondément. La nouvelle « orthodoxie » est ainsi respectée : la formation de l'État est bien disjointe du processus d'indianisation.

De façon symptomatique, lorsque la planification géométrique et cosmologique de Óc Eo vient finalement à faire l'objet d'un commentaire, l'objectif demeure toujours d'en relativiser la signification historique (se verraient ainsi justifiées les omissions faites par ailleurs). Une première démarche consiste à défendre l'hypothèse d'une datation tardive de la ville, de sorte que celle-ci ne nous renseignerait ni sur la formation de l'État, ni sur une éventuelle indianisation. Une seconde démarche véhicule une sorte d'hyperscepticisme refusant de se prononcer sur le caractère indianisé du tracé géométrique de Óc Eo. Les travaux qui se sont efforcés jusqu'à présent de concilier à la fois l'ancienneté de la ville de Óc Eo et le caractère indianisé de ses vestiges sont avant tout ceux de Malleret ou de Cœdès, mais au prix d'une hypothèse coûteuse et insoutenable aujourd'hui : Óc Eo comme l'œuvre de colons indiens.

13. Paradoxalement, la mention de « l’urbanisme » remarquable de Óc Eo paraît plus fréquente dans les travaux émanant d'auteurs non spécialistes du Cambodge ancien ou dans ceux à vocation plus généraliste et qui, pour cette raison, offrent souvent un aperçu moins orienté des données disponibles. Voir, par exemple, Higham $2002: 236$ ou encore les premiers écrits de vulgarisation de Groslier (1961:50-54).

14. Codès 1964: 75; voir aussi les pages 41-42. L'accent y est mis sur les importations issues du monde méditerranéen (ou supposées telles).

15. Jacques 1986; Jacques \& Lafond 2004: Vickery 1998, 2003-04.

16. Groslier 1979. Le tracé « en damier » au sud-ouest du Baray occidental (à Angkor), interprété par Groslier comme la ville de "Banteay Chhoeu », a fait récemment l'objet d'une tout autre analyse par Christophe Pottier, que nous discuterons plus bas. Nous conserverons, par convention. lexpression de "Banteay (hhoeu» pour désigner cette « ville sous le har " ». tout en prenant note du fait que ce toponyme pourrait désigner une enceinte situéc un peu plus à lest (Pottier 2002: 121, n. 13). 
À travers chacune de ces thèses, c'est la question de l'indianisation qui nous semble être laissée en suspens. Comme nous le verrons, ce n'est pas le moindre intérêt de Óc Eo que de nous obliger à reconsidérer le contenu d'une telle notion. Auparavant, il nous semble nécessaire de faire à nouveau la démonstration et du caractère indianisé de son plan géométrique et de son ancienneté. Sur ces deux aspects, Malleret avait déjà attiré l'attention, mais son intérêt porté aux objets « exotiques » d'une part, et son hypothèse de colons indiens de l'autre, auront suffi à reléguer au second plan ses observations à ce sujet. Sa présentation du plan de Óc Eo demande par ailleurs à être revue sur plusieurs points.

\section{Un modèle cosmologique indien}

\section{Un plan en échiquier}

La ville se présentait comme un vaste rectangle traversé dans le sens de la longueur par un canal médian présentant une orientation nord-nord-est/sud-sud-ouest de 25 degrés par rapport au nord (pl. 4-5).

Le plus petit côté mesure un peu moins de $1,5 \mathrm{~km}$. La longueur du plus grand côté ne peut être déterminée aujourd'hui avec certitude. Si trois des côtés de l'enceinte sont assez nettement visibles sur les anciennes photographies aériennes de la région, la localisation de la limite septentrionale de la ville est beaucoup moins évidente. Malleret s'est pourtant montré assez sûr de son fait sur cette question, en soutenant que la ville mesurait en longueur le double de sa largeur et formait ainsi un rectangle d'environ $1,5 \times 3 \mathrm{~km}$ (1959-1963, vol. I : 198). Cette estimation suscite certaines réserves. En premier lieu, on considérera les conditions dans lesquelles elle a été obtenue. Elle ne résulte pas de constations faites sur le terrain ou à partir de photographies aériennes, mais d'observations faites à bord d'un bombardier à l'occasion de survols en piqué au-dessus du site. Malleret affirme avoir ainsi repéré distinctement le quatrième côté de l'enceinte, tout en précisant que les traces observées sur le sol apparaissent très atténuées et discontinues. Aucune prise de vue qui aurait été faite à cette occasion ne permet aujourd'hui de s'en assurer. En admettant que Malleret n'ait pas confondu cette hypothétique portion de l'enceinte avec l'un de ces anciens canaux que l'on voit orienté de façon identique à proximité du site (selon son hypothèse, l'enceinte de la ville longerait en effet l'ancien canal de $\mathrm{Ba}$ Thê), il lui restait encore, de retour au sol, à restituer correctement sur un plan la localisation des tracés ainsi observés lors de ces brefs passages en piqué. C'est là une autre source potentielle d'erreur au regard de la précision recherchée.

Que l'enceinte ait bien formé un rectangle fait peu de doute : le tracé des côtés est et ouest (ou sud-est et nord-ouest), tel qu'il peut être observé sur les anciennes photographies disponibles, le montre clairement. On peut être aussi à peu près sûr que la ville se prolongeait au-delà du site de Giồng Cát et de ses environs immédiats. Dans le cas contraire, les douves de l'enceinte recouperaient la zone de tertre correspondante et on comprendrait difficilement pourquoi elles n'y seraient pas plus distinctement visibles (elles devraient en effet dessiner des zones sombres de dépressions sur les zones plus claires de levées de terre). Au-delà, rien n'est sûr et seules des fouilles permettront d'être définitivement fixé. Mais deux séries d'indices méritent d'être relevées et permettent de proposer une hypothèse de travail raisonnable et sensiblement différente de celle de Malleret : les tracés des deux côtés est ct ouest de l'enceinte s'interrompent sensiblement 
à la même hauteur: c'est à cette même hauteur que convergent un ensemble de canaux qui intègrent la ville au sein de l'ancien réseau hydraulique sillonnant cette partie du delta. Nous sommes ainsi amené à situer la limite septentrionale de l'enceinte immédiatement au-delà du tertre de Giồng Cát. On obtiendrait ainsi une enceinte rectangulaire d'un rapport de 3 à 4 entre petit et grand côté, mesurant environ $1,5 \mathrm{~km} \times 2 \mathrm{~km}$ (mesures à augmenter d'approximativement 250 mètres si elles sont prises sur la douve externe de l'enceinte). Il n'est peut-être pas indifférent que le centre géométrique d'un tel rectangle corresponde à l'intersection entre deux canaux majeurs du carroyage interne de la ville; on est là entre le tertre de Gò Cây Thị et celui, éponyme, de Gò Óc Eo, dans une zone d'occupation et d'activité remarquable à l'intérieur de la ville. Notons qu'à l'inverse, le centre géométrique impliqué par l'hypothèse de Malleret ne correspond à aucun point notable dans la topographie de la ville (pl. 6).

Malleret décrit l’enceinte de la ville ancienne comme étant composée de cinq douves concentriques qui apparaissent sur les photographies aériennes des années 1920 et 1950 comme une succession de lignes parallèles, alternativement sombres et claires. Alors que la plaine de Óc Eo n’étail pas encore mise en rizières, Mallerel s'est eflorcé de retrouver sur le terrain des micro-élévations qui signaleraient la succession des douves. Comme l'auteur en convient lui-même, les indices récoltés sont peu concluants : "En un point seulement, écrit-il, marchant au Sud, j'eus la sensation de franchir une série de dépressions, larges de sept à huit mètres chacune, séparées par des talus de même dimension approximative. Je refis cinq fois ce parcours [...]. Invariablement je trouvai cinq dépressions et quatre talus, nombre qui correspond aux lignes parallèles révélées par l'observation aérienne " (ibid., p. 189). Il est, en réalité, peu probable que cette micro-topographie nous renseigne sur les dénivellations des douves : ni l'espacement entre les dépressions, ni la longueur totale parcourue par Malleret ne correspond à ce que l'on observe sur les photographies aériennes. Aujourd'hui, après l'extension de la riziculture à l'ensemble de la région, seule la fouille, comme on le verra, est en mesure de nous renseigner sur le profil de l'enceinte.

Au demeurant, il n'est pas sûr que l'on doive compter cinq douves comme l'écrit Malleret ${ }^{17}$. Il nous semble plus juste d'écrire que l'enceinte en elle-même ne se compose que de quatre douves, espacées à égale distance les unes des autres. S'y ajoute une douve intérieure, légèrement plus éloignée des quatre douves extérieures, et formant un canal pourtournant intégré au quadrillage interne de la ville, lui-même composé d'une série de canaux se croisant à angle droit (pl. 3).

Le principal de ces canaux est celui du Lung Lơn. Il traverse la cité de part en part, selon son axe médian, dans le sens de la longueur. Il se prolonge bien au-delà au nord-est et au sud-ouest de la ville, mettant celle-ci en relation avec, au sud-ouest, la rivière de Takéo et, au nord-est, la rivière de Long Xuyên (la première se jette dans le golfe du Siam, la seconde dans le bras occidental du Mékong) ${ }^{18}$. Deux autres canaux, de part et d'autre du Lung Lơn et parallèles à celui-ci, subdivisent les parties est et ouest de la ville en deux moitiés égales. Orientés perpendiculairement aux précédents, quatre nouveaux canaux subdivisent transversalement la partie occidentale de la ville.

17. Le relevé des douves que propose la planche XV de L'archéologie du delta du Mékong prête particulièrement à confusion à ce sujet (Malleret 1959-1963, vol. I).

18. Cif. Bourdonneau 2003b : 261 et fig. 3-4. 
Il semble que le même carroyage se retrouvait dans la partie orientale mais celle-ci est, de manière générale, beaucoup moins lisible sur les photographies aériennes, de sorte que la question de l'éventuel inachèvement du tracé des canaux reste ici ouverte. Quoi qu'il en soit, on obtient une division théorique de l'espace en $4 \times 5$ soit 20 « quartiers " (pl. 7).

\section{L'Inde pour modèle}

Un plan quadrangulaire, une enceinte composée d'un système de douves concentriques (et autant de levées de terre), un carroyage interne en échiquier : l'ensemble de ces caractéristiques laisse, à nos yeux, peu de doute sur le caractère indianisé du tracé de la ville de Óc Eo. Nous reviendrons plus loin sur ce que recouvrent à notre sens les termes " indianisé » et " indianisation ». Nous examinerons tout d'abord les raisons pour lesquelles ce que nous sommes tenté d'admettre sur le ton de l'évidence a été nié ou mis en doute (lorsqu'il n'a pas été préféré de le passer sous silence).

La prudence de Malleret s'est transformée en scepticisme chez nombre de ses lecteurs. Malleret a bien été tenté d'interpréter le plan régulier de Óc Eo selon les modèles d'urbanisme du monde indien en proposant de reconnaître dans le dispositif qui délimite le périmètre de la ville «l'évocation d'un système cosmologique englobant des continents et des océans périphériques ". Si l'hypothèse lui semble problématique, c'est que le nombre de cinq douves ne correspond pas à ses yeux au nombre attendu, à savoir sept comme les sept océans (et continents) concentriques entourant le mont Meru des cosmologies des Purāna. La même objection se retrouve dans Nagara and Commandery de Paul Wheatley, qui a adopté une position plus tranchée : " in the absence of a written commentary on this or any other city of Fu-nan, it is hazardous to speculate on the possible significance of the distinctive layout of the city at Oc-èo [...]. Neither the air photographs published by Malleret nor his own plan of the city show any affinity with Indian cosmology $»(1983: 130)$.

$\mathrm{Si}$, selon Wheatley, la forme de l'enceinte de Óc Eo ne livre guère d'indices d'un symbolisme indien, ce serait non seulement parce que le nombre des douves ne serait pas le bon, mais aussi parce que l'orientation cardinale prescrite par les traités serait ici clairement manquante, tandis qu'elle se trouve respectée dans d'autres cités d'Asie du Sud-Est (ibid., p. 131).

Là où Malleret suggère un rapprochement, Wheatley entend souligner tout le contraste de ce tracé avec les plans des cités khmères plus tardives. L'orientation cardinale mais aussi la présence d'un mont Meru au centre géométrique de l'espace urbain, ce sont là, souligne l'auteur, des caractéristiques majeures de la dimension cosmologique des villes khmères "classiques " qui font défaut à Óc Eo, dont la montagne sacrée (l'actuel Ba Thê), observe-t-il justement, réside à l'extérieur de l'enceinte urbaine (ibid., p. 135). Au final, écrit-il, si une lecture cosmologique du tracé urbain de Óc Eo doit être proposée, il faut chercher dans d'autres cosmologies que les cosmologies hindoues ou bouddhiques pour en identifier le modèle. Wheatley propose ainsi quelques brèves comparaisons, en particulier avec le site de Cổ Loa et ses enceintes, mais sans paraître lui-même bien convaincu (ibid., p. 130).

Il est possible que les remarques de Malleret sur les connaissances lacunaires du tracé de la ville, en même temps que son inclination à reconnaître dans ce tracé l'œuvre de colons indiens, aient conduit à l'inverse Wheatley à prendre nettement position contre 
l'hypothèse d'un modèle indien. Cependant. les objections qu’il soulève paraissent bien pauvres.

Que le nombre des douves ne s'élève pas ici à sept n'est en rien un obstacle à l'hypothèse d'un symbolisme indien. Tout d'abord parce que, à une exception près ${ }^{19}$, on n'en connaît guère d'exemples ailleurs, que ce soit en Asie du Sud ou en Asie du Sud-Est. Les principaux traités indiens sur la structuration des villes ne prescrivent d'ailleurs pas un tel nombre de douves ${ }^{20}$. L'existence même d'une série d'enceintes concentriques (douves, levées de terre, murs) est loin d'être la norme. Rappelons, si nécessaire, que, dans le Cambodge ancien, des villes comme celles dites de Banteay Chhœu, Banteay Prei Nokor ou encore Angkor Thom, ne comprenaient qu'une seule douve dans leur dispositif d'enceinte.

La même remarque vaut pour l'orientation cardinale. Elle est, certes, bien respectée à Angkor Thom et à Banteay Chhœu mais elle ne l'est pas à Sambor Prei Kuk ou à Koh Ker. qui furent deux capitales également importantes du Cambodge ancien ${ }^{21}$. Enfin, contrairement à ce que laisse entendre Wheatley, la présence d'un mont Meru prenant la forme d'un temple et/ou d'une colline au centre géométrique de la ville peut difficilement passer pour une caractéristique majeure de "l'urbanisme classique " du Cambodge ancien. Car, en l'état des connaissances, elle est surtout une spécificité d'Angkor Thom, la capitale bâtie par Jayavarman VII à la fin du XII' siècle et centrée sur le temple-montagne du Bayon. C'est là, certes, une illustration spectaculaire de cette centralité, mais elle n'en paraît pas moins constituer une innovation tardive par rapport aux cités antérieures comme Wat Luong Kau (au pied de Vat Phu), Banteay Chhœu ou Sambor Prei Kuk. Une telle spécificité peut, à notre sens, ètre comprise sans considérer les nombreux changements qui caractérisent et distinguent ce «long $X I^{\circ}$ siècle » dans l'histoire du Cambodge. Ajoutons que la centralité, l'enceinte prenant des allures de remparts fortifiés et les portes monumentales d'Angkor Thom 22 rapprochent la cité de Jayavarman VII des capitales bouddhiques thaïes et birmanes qui lui font suite (à cette différence importante que celles-ci sont désormais centrées sur les palais du souverain).

Il est vrai que Wheatley songeait probablement aussi à une première Angkor (Yaśodharapura) bâtie par Yaśovarman à la fin du IX siècle, dotée d'une enceinte avoisi-

19. A notre connaissance, lancienne ville de Muang Sing est la seule dont le dispositif de l'enceinte repose sur le chiffre 7 (ici sept levées de terres). À tout le moins, elle est, à notre connaissance, la seule qui puisse être rattachée à $1^{\circ}$ histoire du Cambodge ancien. Une partie des vestiges retrouvés à l'intérieur de l'enceinte ont été attribués au style du Bayon et au règne de Jayavarman VII. Dans une région relativement excentrée, elle se situe en Thaïlande, à proximité de la ville de Kanchanaburi, dans la province du même nom. Les sept levées de terre délimitent les seuls côtés est, ouest et nord. La ville prend appui au sud sur les berges de la rivière Khwea Noi.

20. Pour un aperçu du contenu de ces ouvrages et de leur intérêt pour le Cambodge ancien, voir Gaucher 2004 : 77-81 (et discussion infra).

21. Comme le note lui-même Wheatley, l'axe principal de Óc Eo, matérialisé par le canal du Lung Lơn, suit une orientation Nord-Est/Sud-Ouest, voisine de celle du drainage de la nappe d'inondation dans ce secteur du delta. Que l'orientation de la ville ait été en partie déterminée par un tel facteur n`invalide en rien 1 'hypothèse d’une référence à un modèle indicn. Et, comme l’autcur l'ajoutc par ailleurs, la direction du Nord-Est n'est pas sans symbolisme cosmique (Wheatley 1983 : 131 ; Paris $1941)$.

22. A suivre les premiers résultats des travaux menés par Jacques Gaucher sur Angkor Thom, il faudrait ajouter à cette liste un plan en échiquier caractérisé par un maillage désormais plus serré (Gaucher 2004). 
nant, selon la restitution proposée par Victor Goloubew, les quatre kilomètres de côté et centrée sur le Phnom Bakheng. Cependant, Bernard Philippe Groslier ou, plus récemment, Christophe Pottier ont montré combien la restitution de cette enceinte par Goloubew était problématique ${ }^{23}$. Notons néanmoins, pour faire bonne mesure, que l'hypothèse d'un plan quadrillé au pied du Phnom Bakeng ne peut à ce jour être totalement exclue. Le tracé du parcellaire au sud et à l'est du Phnom est susceptible d'être interprété en ce sens, mais la ville ainsi restituée serait bien moins vaste que celle imaginée par Goloubew. Une telle hypothèse, qui reste bien sûr pour l'heure à étayer, laisse par ailleurs en suspens la place du Phnom Bakheng au sein d'un tel tracé.

À notre sens, la référence à un modèle cosmologique indien fait donc aussi peu de doute dans le cas de Óc Eo que dans celui des villes géométriques postérieures du Cambodge ancien ${ }^{24}$. En revanche, il va de soi que subsistent de nombreuses incertitudes sur l'interprétation précise qu'il convient de proposer des particularités prises par un tel modèle à Óc Eo (comme le nombre des douves ou la trame spécifique du carroyage). Plusieurs difficultés se présentent ici.

En ce domaine comme en d'autres ${ }^{25}$, il est à peu près impossible de déterminer quels ont été les écrits porteurs du modèle en question et, de là, de comprendre les spécificités des lectures qui en ont été faites. La diversité des traités normatifs indiens, les incertitudes sur leur chronologie et sur leur diffusion rendent la démarche hasardeuse ${ }^{20}$.

Ces difficultés ne concernent pas la seule littérature technique des traités, mais aussi les grands textes exposant les conceptions cosmologiques dont cette littérature est supposée se faire l'écho. Wheatley se réfère spontanément à la représentation cosmographique qui prévaut dans les Purāna, à savoir celle des sept mers et continents ou «îles » (dvipa) entourant concentriquement le Jambu. Cependant, il ne va pas de soi que c'est bien cette image-là qui prédominait dès les premiers siècles de notre ère (date de Óc Eo,

\section{Croslier 1979 : 174; Pottier 2000a. Voir aussi Gaucher 2004: 63.}

24. Certes, même dans le cas de ces cités, il est toujours loisible de s interroger sur le caractère indianisé ou non de leur planification géométrique. Il faut bien reconnaître que l'exercice est quelque peu académique. Dans son étude sur Angkor Thom, Gaucher s'y prête de bonne grâce en se demandant si le plan régulier qu’il propose de restituer ne pourrait avoir été le résultat d’autres déterminations : un parcellaire agricole antérieur à la fondation de la ville, un modèle de ville proprement " autochtone ", l'urbanisme des villes chinoises. Pour conclure. sans surprise. que c’est une lecture « indienne » qu'il proposera du plan d'Angkor Thom (Gaucher $2004: 78$ ).

25. Voir les remarques de Bruno Dagens sur l’architecture du temple (1994:270).

26. Certes, cela $n$ `interdit pas de raisonner à partir de ce que l'on connaît. La démarche a été récemment tentée par Jacques Gaucher, proposant de lire les grandes caractéristiques du plan d'Angkor Thom à la lueur de trois ouvrages indiens : l'Arthaśástra de Kautilya. le Mänasāra et le Mayamata. Lauteur parvient sans peine à mettre en évidence différentes analogies entre l'ancienne capitale khmère et les exigences des traités indiens. L'exercice donne, si nécessaire, un peu plus de poids au constat du caractère indianisé de cet urbanisme. La démarche présente aussi des limites évidentes du fait qu elle conduit naturellement à retenir des traités ou de la réalité archéologique ce qui illustre au mieux leur rapprochement. L’analyse de Gaucher joue, par exemple, de l'ambiguïté de la distinction faite par lauteur entre "Palais royal » (un vaste « îlot fortifié » dans le nord-ouest de la ville) et "Résidence royale" (délimitéc par une enceinte incluse dans l" "îlot fortifié "). Lorsqu il s"agit de prêter attention aux dimensions du Palais royal décrites dans les traités. lauteur les compare avec celles de l" «îlot fortifie ». Lorsqu il traite de la position du Palais royal au sein d"une division concentrique de la ville évoquée par les traités, il se tourne alors vers ee qu il appelle la « Résidence royale " ( $s$ intégrant à l'intérieur de ce qui serait la zone centrale daiva par les traités). Voir (jaucher $2004: 79-81$ et lig. 24. 
comme nous le verrons) de part et d’autre du golfe du Bengale. Less datations des Purāna demeurent, là encore. très incertaines et leurs descriptions font suite à une très longue tradition de représentations cosmographiques. Citons simplement le Mahähhārata. où la description de sept continents et océans concentriques est absente. La centralité du Meru ou Sumeru y est bien évoquée, mais la montagne mythique est entourée ici de quatre " îles " réparties selon les orients"?

Quand bien même on serait en mesure d`identifier la représentation cosmographique ayant présidé au plan d'une ville, une autre difficulté tient au fait que sa mise en ouvre dans le paysage ne peut en proposer qu'une reproduction partielle. Le monde malais offre d'utiles points de comparaison qui illustrent tout l'écart pouvant exister entre une idée de ville et sa traduction sur le terrain. Les textes malais, observe à ce sujet Daniel Perret, font souvent mention de cités royales à sept enceintes, ce qui ne se rencontre guère sur le terrain. Cependant, la littérature évoque également un rite de circumambulation effectué à sept reprises autour de la cité (à l’occasion notamment d’un mariage royal). " En faisant ainsi sept fois le tour d'une enceinte unique, écrit Perret, le souverain parcourrait symboliquement le monde et prendrait ainsi possession de son royaume dont le centre est constitué par le palais $\gg(1999: 85-86)$.

L'exemple des cités malaises peut également servir à illustrer une dernière difficulté que soulève l'interprétation du plan de Óc Eo. Il fait peu de doute que le système à sept enceintes des textes malais remonte à une conception indianisée du monde. Mais ce symbolisme fait l'objet d'une réinterprétation à la suite de la conversion des souverains à l'islam, et notamment sous l'influence du soufisme : "Les sept enceintes ne symboliseraient plus alors les sept dvipa et samudra mais les sept étapes qu'un individu, en particulier le sultan, doit franchir pour devenir l'Homme parfait » (ibid., p. 86). La référence à un modèle cosmologique purāṇique perdure tout en se prêtant à un symbolisme qui lui est étranger. Au sein de l'historiographie sur le Cambodge ancien, ce type de processus est devenu un lieu majeur de débat. C'est en effet toute la question de l'indianisation que soulève l'adoption de représentations cosmographiques issues du monde indien. Si l'on admet l'hypothèse de cette adoption, il reste à se demander, selon la formule d'Oliver Wolters (1999:109-110), quel est le « sens " pris localement par ces représentations? Disons simplement, pour l'heure, et même si le sujet se prête mal aux formules lapidaires, que l'on doit envisager simultanément un " usage khmer » et une « connotation indienne » des représentations ainsi adoptées, et non pas un « usage » et une « connotation » qui seraient tout à la fois soit khmers, soit « indiens » (ce qui revient, dans un cas, à nier la réalité khmère, et dans l'autre, à vider entièrement le modèle de son sens indien). Qu'il s'agisse de plans urbains ou de toute autre pratique empruntée à l'Inde, leur compréhension implique de faire l'hypothèse de cette sorte de « jeu » sur les représentations indiennes. Cela complique bien sûr sensiblement toute tentative d'interprétation. Clairement, nous ne sommes pas en mesure de pouvoir expliquer tel nombre de douves ou de « quartiers » spécifique à un plan de ville. Cela n'invalide pas pour autant la notion d'indianisation.

27. Renou 1985:547. Les représentations du Mahäbhärata concordent avec celles des textes bouddhiques anciens. Dans la littérature védique. lespace est conçu comme un océan, divisé en deux. trois ou quatre mers (ibid.. p. 332). Selon un passage de l'Atharvaveda. " drei sind der Frden. sagen sie, und drei der Himmel. drei sind der Atmosphären und vier der Ozeane " (Kirfel 1920: 17). 


\section{Une fondation au début de notre ère. Spéculations anciennes et données récentes sur la datation de la ville}

La datation la plus tardive qui ait été proposée pour le tracé géométrique de Óc Eo a été formulée par Jean Boisselier. L'hypothèse retenue par l'auteur a de quoi surprendre : « Les plans barlongs délimités par de nombreux fossés et talus, écrit-il, rappellent [...] nombre de villes de la période d'Ayuthya et les anciens tracés de Suphanburi, Ratburi, Nakhon Si Thammarat ... et même le plan de Lovêk, capitale post-angkorienne... Ainsi sommes-nous tenté de considérer la ville d'Óc Eo (et non 'le port' comme on l'écrit parfois) comme une fondation de la période d'Ayuthya sur un site beaucoup plus ancien en vue d'opérations militaires contre le Cambodge » (1992: 283). Antérieurement aux grands plans géométriques du Cambodge ancien, ce sont les tracés plus irréguliers, plus ou moins inspirés par la topographie locale, qui signalent, aux yeux de Boisselier, des villes « vraiment très anciennes ». L'auteur cite, pour le Cambodge, les sites d'Angkor Borei ou Gianh Thanh (à la frontière avec le Vietnam), mais songe surtout aux anciennes cités du bassin de la Menam Chao Phraya sur lesquelles il a lui-même beaucoup travaillé. Ce rapprochement avec les sites de la Thaïlande centrale constitue en effet le fond de son argumentation. Boisselier passe en revue l'ensemble des artefacts collectés à Óc Eo pour montrer qu'ils définissent une culture matérielle qui trouve son origine dans le bassin de la Menam Chao Phraya ou sur la péninsule. Pour la statuaire, l'auteur cite l'exemple d'un Viṣnu de Óc Eo qualifié d' ' image aberrante » et qui ne s'expliquerait que par référence aux idoles de la tradition de Chaiya (sur la péninsule) identifiées comme les plus anciennes de l'Asie du Sud-Est. De la même façon, les Buddha en bois provenant du delta du Mékong relèveraient " de traditions iconographiques indonésiennes qui ne permettent de les attribuer qu'au vill" siècle environ et de les intégrer ainsi au courant d'influences Śrīvijaya » (ibid., p. 281 ${ }^{28}$. Il en irait de même des nombreux objets de parures qui attesteraient, selon Boisselier, des contacts suivis avec la Thaillande aux $V I I^{-}-I X^{\mathbb{C}}$ siècles. Ailleurs, l'auteur attire l'attention sur les intailles épigraphiques ou les éléments de décor de style « andhra » attestés sur le site de Óc Eo mais qui se retrouveraient à l'identique sur des sites comme U Thong ou Khlong Thom.

À suivre Boisselier, Malleret se serait donc lourdement trompé sur l'interprétation à donner de l'histoire de Óc Eo. Les vestiges mis au jour, loin de définir une culture matérielle propre au delta, témoigneraient surtout du dynamisme des régions situées plus à l'ouest (péninsule et Thaïlande centrale), qui lui auraient transmis les apports des mondes indien, méditerranéen ou même indonésien (Boisselier 1992 : 284). Le "véritable substrat" du delta, selon les termes de Boisselier, serait représenté par une tradition préhistorique mégalithique, attestée à Óc Eo par le matériel céramique et qui serait étrangère à ces apports. Ne pouvant être rattachée ni au foyer culturel du bassin de la Chao Phraya, ni à cette tradition mégalithique, la réalisation du tracé de Óc Eo se voit repoussée de plus d'un millénaire par rapport aux datations usuelles.

Il ne saurait être question de sous-estimer la contribution de Boisselier à notre connaissance du Cambodge ancien. Mais il ne fut guère inspiré ici en proposant de dater l'urba-

28. L'auteur ne s'arrête guère ici sur les datations $C^{1+}$ de Buddha publiées par Malleret (1959-1963. vol. IV : 164). Il est vrai qu une nouvelle série d'analyses mériterait d'être programmée. Les datations de Malleret (pionnières en ce domaine) présentent, entre autres, l’inconvénient de ne pas être calibrées. Après calibrage, on obtient un étalement considérable des dates dans le temps. Elles oscillent alors entre le $\|^{\circ}$ et le $x^{\circ}$ siècle (je remercie Pierre-Yves Manguin pour m’avoir communiqué le résultat de ces dates calibrées). 
nisme de Óc Eor de la période d'Ayuthya. Bien mal étayée. l'hypothèse n'a d'ailleurs pas été suivie et il n'y a sans doute pas de raison de s'y attarder davantage ${ }^{20}$. En revanche. l'opinion de Boisselier selon laquelle les contacts de Óc Eo avec les mondes indien ou méditerranéen n'ont pu s'établir que par l'intermédiaire de la Thaïlande (bassin de la Chao Phraya et péninsule) est plus largement partagée. Il y avait là, écrit Boisselier, une sorte de nécessité imposée par les réalités géographiques et les impératifs de la navigation ancienne. Rien de ce qui parvenait dans le delta du Mékong, en provenance de l'Ouest et antérieurement au $\mathrm{VII}^{\mathrm{E}}$ siècle (voire jusqu'au $\mathrm{IX}^{\mathrm{C}}$ siècle), ne pouvait utiliser d'autres voies que celle-ci. Boisselier n'hésitera pas, dans un autre travail, à placer le cœur du Funan à U Thong et à suggérer que les conquêtes de Fanshiman rapportées par les auteurs chinois furent menées non pas depuis le delta du Mékong vers les régions plus à l'ouest, mais depuis la Chao Phraya vers le delta ${ }^{30}$.

\section{Óc Eo de l'autre côté de la "barrière"?}

« Un pont et une barrière », telle est la formule adoptée par Stanley O'Connor pour résumer ce rôle joué par la Thaïlande et, singulièrement, la péninsule à l'égard du delta et de la péninsule indochinoise (1972:11,39-40). Sans remettre en cause, comme le fait Boisselier, la localisation du Funan, les auteurs sont nombreux à avoir adopté cette définition de la péninsule comme une première étape et un relais de l'indianisation vers le Funan "'. S'expliquerait de cette façon le double décalage que constateraient les historiens de l'art entre les réalisations funanaises et, d'une part, les productions de la péninsule, d'autre part, celles du sous-continent indien.

\section{Viṣnu et linga}

Le premier décalage, celui entre les deux rives du golfe du Siam, se manifesterait en particulier dans les différences stylistiques entre les images de Viṣnu (ou de VāsudevaKrṣna) retrouvées sur la péninsule (à Chaiya, identifié au Panpan des auteurs chinois) et dans le delta du Mékong (à Óc Eo). Il ne semble ainsi faire guère de doute que le Viṣnu de Chaiya est plus proche des modèles indiens et a priori plus ancien que le Viṣnu de Óc Eo. Daté au plus tard de 400 de notre ère par S. O'Connor, l'exemplaire de Chaiya serait ainsi la plus ancienne statue hindouiste découverte en Asie du Sud-Est. L'image de Óc Eo daterait pour sa part du $\mathrm{v}^{\mathrm{c}}$ siècle de notre ère. Pour autant, la comparaison est bien insuffisante pour étayer l'hypothèse d'un décalage. En premier lieu, elle ne prend pas en compte la représentativité des images qui sont comparées. Si le Viṣnu de Óc Eo est très certainement postérieur à celui de Chaiya, il ne va pas de soi qu'il s'agisse de

29. Disons simplement un mot sur les commentaires méthodologiques qui accompagnent la lecture critique des travaux de Malleret par Boisselier. Ce dernier observe que les pillages dont le site de Óc Eo a été victime rendent à peu près impossible de connaître réellement la provenance des objets acquis auprès des fouilleurs clandestins. Indéniablement, les pillages induisent une perte d'information. Mais l'excès de prudence ne vaut pas rigueur. Quand bien même les sondages stratigraphiques menés par Malleret furent peu nombreux et réalisés dans des conditions peu satisfaisantes, l'ensemble des données réunies par celui-ci laissait peu de doute non seulement sur l'identification de Óc Eo comme lieu d'origine des objets collectés, mais aussi comme lieu de production d'une partie d'entre eux (cf. infica).

30. Boisselier 1965. discuté dans Vickery 2003-04: 118-119.

31. L'hypothèse est particulièrement en faveur parmi les historiens d’art (cf. Griswold 1966:57: JaccHergoualc'h 1990: 131: Dalsheimer 1998:489). 
la plus ancienne image hindouiste du site et, de manière plus générale, du plus ancien témoignage d'un emprunt de traits culturels indiens dans le delta du Mékong.

En particulier, l'hypothèse ne tient pas compte des datations que l'on peut attribuer à deux linga naturalistes provenant de Óc Eo. Ces linga se caractérisent par une forme du gland très allongée ${ }^{32}$. Louis Malleret a souligné leur parenté avec une pièce quasi identique du Sud de l'Inde datée par T. A. Gopinatha Rao du tournant de notre ère ${ }^{33}$. Comme le souligne Robert Brown, les linga publiés par Malleret peuvent être également rapprochés des exemples de la première période kuṣaṇa, aux environs du $1^{\mathbb{E}}$ siècle de notre ère ${ }^{34}$. Cependant, loin de conclure à l'ancienneté des linga de Óc Eo, et tout en concédant qu'une telle possibilité ne peut être exclue, l'auteur préfère adopter à son tour les datations usuelles proposées pour les linga sud-est asiatiques : les exemples les plus réalistes seraient datés de la fin du $v^{\text {}}$ ou du vi $\mathfrak{l}^{\bullet}$ siècle tandis que ceux de forme plus stylisée

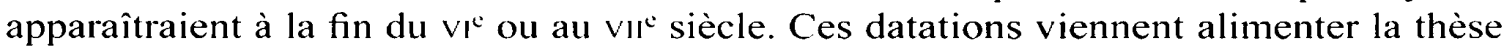
d'un double décalage : tout d'abord entre les deux rives du golfe du Bengale, puis entre les côtes du golfe du Siam. Entre les premiers linga kuṣạna et les premières réalisations d'Asie du Sud-Est, au minimum trois siècles se seraient écoulés selon Brown, si bien que, lorsque les premiers linga du golfe du Siam font leur apparition, c'est dans un style réaliste qui serait abandonné depuis longtemps sur le sous-continent.

Les raisons pour lesquelles Brown estime improbable l'ancienneté des linga de Óc Eo sont pourtant bien minces. L'auteur renvoie, sans plus de précisions, aux datations des autres trouvailles issues du site. Or, celles-ci, loin de s'opposer à une datation haute des linga, s'y accordent assez bien. À commencer par les datations $\mathrm{C}^{14}$ réalisées récemment, à l'occasion de la reprises des fouilles sur le site dans le cadre de la mission "Archéologie du delta du Mékong ». On songe en priorité à celles obtenues pour l'enceinte de la douve sur laquelle nous allons revenir bientôt. On peut citer également les datations des premiers niveaux d'occupation du tertre éponyme de Gò Óc Eo. Elles définissent une fourchette chronologique qui couvre le début de notre ère.

\section{Sceaux et intailles}

Dès les premiers travaux de Malleret, on a disposé de données témoignant de l'activité de Óc Eo antérieurement au $I V^{2}$ siècle de notre ère. C'est le cas des fameux sceaux inscrits. L'analyse paléographique permet de les situer globalement entre le $\|^{\circ}$ et le $\mathrm{V}^{\mathrm{C}}$ siècle (écriture gupta ou plus ancienne). À suivre J. Filliozat, une certaine densité de témoignages coïncide avec les $11^{\circ}-11 I^{\circ}$ siècles (pour au moins neuf inscriptions) ${ }^{35}$. Les pièces les plus archaïques seraient proches de certaines inscriptions indiennes de 120 et 150 de notre ère. « D'autres se situeraient aux environs de 300 A. D., tandis qu'un groupe plus récent se placerait dans les $I V^{*}$ et $v^{*}$ siècles ${ }^{36}$.

32. Un linga très proche stylistiquement se trouve aujourd ${ }^{\circ}$ hui à Angkor Borei (je remercie Bertrand Porte de $m$ en avoir signalé l'existence).

33. Malleret 1959-1963, vol. I : 381 et $\mathrm{pl}$. LXXXa/c.

34. Brown $1992: 47-49$ (se référant aux travaux de Giritli von Mitterwallner).

35. Malleret 1959-1963, vol. $111: 312$.

36. Thid., p. 286, 312. Quelques exemplaires pourraient être légèrement postéricurs au ve siecle (Malleret 1959-1963, vol. Il : 325). L'analyse des sceaux inscrits retrouvés sur d’autres sites d'Asie du Sud-list offre sensiblement le même éventail de datations mais davantage concentrées autour de la limite basse de la chronologie valable pour ÓC Eo. A Hailin, en Birmanie, l'unique sceau mis au jour est daté du 
Certes. il est possible d'envisager ponctuellement que tel ou tel sceau inserit ait pu appartenir à un marchand indien, ou qu 'il ait été importé à l’instar de certaines « intailles méditerranéennes » et du cabochon « d'aspect iranien » retrouvés à Óc Eo. Les tenants de la thèse commerciale sont allés beaucoup plus loin en ce sens. Selon Himanshu Ray, " this profusion of intaglios, seals and stampings of Indian origin in Mainland Southeast Asia would suggest a much more organised network of trade than has hitherto been accepted » (Ray 1991:361). Aux yeux de l'auteur, les sceaux constituent ainsi une catégorie d'objets étroitement associée à l'existence de réseaux de commerce indiens (ibid. p. 356 et Ray $1994: 113$ et suiv.). Leur distribution de part et d'autre du golfe du Bengale fournirait la preuve tangible et d'un commerce aux mains des guildes et marchands indiens et de la présence des agents de ces réseaux de marchands privés en Asie du Sud-Est.

$\dot{\Lambda}$ notre sens. parler d'une "profusion » d'intailles, de sceaux et d'empreintes de sceaux en Asie du Sud-Est est excessif. Privilégier l'hypothèse d'une « origine indienne » relève du simple présupposé. La démonstration de Ray passe sous silence l'existence d'une industrie de la glyptique à Óc Eo, mise en évidence par Malleret ${ }^{37}$. La présence. parmi les objets ramassés sur ce site, de cachets en or anépigraphes est également à souligner ${ }^{3 *}$. Enfin, Ray ne s'attarde pas non plus sur ce qui paraît différencier les corpus de sceaux sud-est asiatiques et indiens. Dans une étude consacrée aux guildes dans l'Inde ancienne, Kiran Kumar Thaplyal dresse la liste des inscriptions portées par les sceaux indiens dont on peut penser qu'ils émanent de guildes ou de corporations (1996: 172-175). Une majorité de ces sceaux proviennent des sites de Basarh (Vaisali), Bhita et Rajghat (Varanasi). c'est-à-dire ceux-là mêmes que Malleret et Ray proposaient de mettre en relation avec les sceaux sud-est asiatiques. Mais relever ponctuellement. comme le font ces deux auteurs, tel nom propre (Visnumitra), telle formule religieuse (jita!n bhagaratā) ou tel motif iconographique (le Nandin), revient à gommer ce qui fait l'intérêt et l'originalité des inscriptions indiennes. On songe ici aux diverses formules utilisées pour signifier que les sceaux inscrits sont précisément ceux de corporations ou guildes : śreñu, nigama (nigamasva), nigamasa ou negamasa, kulika-nigama, śrestî-nigama, śrești-särthavāha-kulika-nigama. C"est parce qu'ils sont associés à de telles mentions que les noms d'individus, les formules religieuses ou les motifs iconographiques des sceaux (ou empreintes de sceaux) retrouvés sur ces sites peuvent être mis en relation avec les activités commerciales de guildes ${ }^{39}$. Aucun des objets inscrits de Óc Eo ne donne à lire des formules comparables. La remarque peut ètre élargie aux sceaux retrouvés ailleurs en

ve siècle. À Kuala Selinsing, en Malaisic, un sceau trouvé en surface est attribué aux $\mathrm{V}^{-V}-\mathrm{VI}^{*}$ siècles. $\dot{A}$ Khlong Thom, sur les trois sceaux inscrits connus à ce jour, l'un est daté paléographiquement du $1^{*{ }^{\circ}}$ $1 I^{\circ}$ siècle: les deux autres porteraient une inscription en écriture Pallava attribuable aux $V I^{\circ}-I X^{\circ}$ siècles (Bronson 1990:217). Enfin à Khao Sam Khaeo, en Thaïlande péninsulaire, un sceau en or récemment

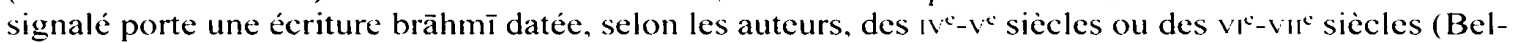
lina $2002: 336$ ).

37. Malleret attire l'attention sur trois cornalines qui montrent autant d’étapes différentes dans la préparation de la pierre pour recevoir une image en creux. Il signale également deux agates à l'état d'ébauche qui montrent que la technique délicate des camées était également pratiquée à Óc Eo (Malleret 1959-1963, vol. III : 278-279).

38. Ihid.. p. 110.

39. Selon Malleret. le motil du taureau ou du bexula bosse peut ètre. dans certains cas, associé au pouvoir politique. On le troure "sur des cachets à Sirkap. Taxila. à Basārh et à Bhĩtā. objets ayant appartenu à des fonctionnaires, agents d'autorité. souvent même officiers de police " (Malleret 19591963. vol. III : 371 1. 
Asie du Sud-Est qui portent, à l'instar des exemplaires funanais, soit des noms propres, soit des formules relatives au don.

Nous ne voyons donc pas de raisons sérieuses de douter que les sceaux inscrits retrouvés à Óc Eo aient été fabriqués localement et/ou aient appartenu à des acteurs locaux, cela dès le $\mathrm{II}^{\circ}$ ou le $\mathrm{III}^{\circ}$ siècle de notre ère. Faut-il mettre en doute la fiabilité des datations proposées pour les sceaux les plus anciens? La paléographie des inscriptions, comme l'analyse stylistique des linga, n'autorise pas de grande précision en ce domaine. L'historiographie a joué de ces ambiguïtés pour repousser aux $I V^{\mathbb{E}}-\mathrm{V}^{\mathbb{2}}$ siècles les plus anciens témoignages de l'indianisation. Elle a évoqué, en ce sens, la possibilité de chevauchements stylistiques et fait l'hypothèse de productions distinctes selon les régions ou les ateliers. On conviendra que cela ne permet pas de concevoir une évolution linéaire qui intégrerait les unes à la suite des autres le petit nombre des pièces connues. Mais il est une tout autre chose de nier jusqu'à l'existence même d'une évolution stylistique.

Privilégier systématiquement des datations tardives (pour des pièces dont chacun s'accorde pourtant à reconnaître le style « archaïque ») conduit à regrouper sous une même période tardive des productions d'allures nettement différentes. L'hétérogénéité de ces corpus devient alors difficilement compréhensible. À tout le moins, la seule hypothèse d'une diversité régionale des styles ne suffit pas à en rendre compte, car elle s'accorde assez peu avec la distribution géographique des objets étudiés. Quand des pièces d'apparence « archaïque » et d'autres qui le semblent moins se retrouvent sur un même site (comme Óc Eo) dont l'occupation s'étale sur plusieurs siècles, et lorsque, $a$ fortiori, d'autres artefacts de provenance identique montrent le même contraste entre formes anciennes et formes plus récentes, il nous semble que nous sommes bien fondés, quoi qu'il en ait été dit, à faire l'hypothèse d'une évolution stylistique.

\section{Le témoignage des sources chinoises}

Les sources chinoises ont, elles aussi, été mobilisées pour montrer le caractère tardif de l'indianisation du Funan et le décalage entre le delta du Mékong et la péninsule Thaï-Malaise. Les historiens de l'art n'ont pas hésité à faire le rapprochement entre leurs observations sur les Viṣnu de Chaiya et de Óc Eo et l'épisode relaté dans le Liangshu ${ }^{40}$ : "Kiao-tch'en-jou (Kauṇinya) était originairement un brahmane de l'Inde. Il y eut une voix surnaturelle qui lui dit : "Il faut aller régner au Fou-nan". Kauṇ̣inya se réjouit dans son cœur. Au sud, il arriva au Panpan. Les gens du Fou-nan l'apprirent; tout le royaume se leva avec joie, alla au-devant de lui et l'élut roi. Il changea encore toutes les règles selon les méthodes de l'Inde " (trad. Pelliot 1903 : 269). Le Liangshu situe cet épisode entre le milieu du Iv" siècle et le second quart du v' siècle, à une époque qui serait donc contemporaine de la réalisation du Viṣnu de Chaiya. Il est vrai également que l'on peut raisonnablement identifier le Panpan avec la région de Chaiya. Il n'en demeure pas moins que l'épisode du Liangshu revêt un caractère légendaire et cette légende nous apprend surtout que la péninsule Thaï-Malaise était perçue comme un point d'atterrage privilégié après la traversée du golfe du Bengale. Mais elle n'autorise pas davantage à verser dans le déterminisme géographique. Que les biens et les hommes aient, en partie, transité par la péninsule avant de parvenir jusqu'au delta n'est certainement pas suffisant pour déterminer la nature et le sens des relations culturelles entre les deux rives du golfe du Siam. Rappelons que ce dernier se traverse en quelques jours et qu'il est curieux que ces quelques jours se transforment en décennies ou en demi-siècles lorsqu'il s`agit d'emprunts 
à l'Inde. Sauf, éventuellement. à supposer un rapport de force particulièrement farorable à la péninsule ou à faire la démonstration d’un choix fait par le Funan à cette époque de ne pas emprunter à l'Inde.

Les sources chinoises permettent d'exclure la première hypothèse. Le Liangshu rapporte les conquêtes funanaises menées par le souverain Fan(shi)man le long des côtes du golfe du Siam au tournant du second siècle de notre ère. Certes, la dizaine de « royaumes » $(g u o)$ qui subirent l'offensive du Funan ne sont pas tous nommés et, parmi ceux qui le sont, certains ne peuvent être situés précisément. Mais, dans chacun des cas, la péninsule Thaï-Malaise, depuis le bassin inférieur de la Chao Praya, au nord, à la rivière de Terengganu, au sud (et sur la côte ouest, de la région de Mergui à celle de Kedah), demeure le meilleur candidat ${ }^{+1}$. Le témoignage des conquêtes de Fan(shi)man ne suffit certainement pas à fonder l'hypothèse d'un « empire » funanais annexant territorialement la péninsule Thaï-Malaise, mais on aurait tort de minimiser l'importance historique de cet épisode en n'y voyant que des raids guerriers sans lendemain. Il est peut-être significatif que le paragraphe sur les conquêtes de Fan(shi)man soit le seul à donner une dimension du Funan de $"$ cinq ou six mille $l i{ }^{+{ }^{+2}}$. tandis que la mesure de $3000 l i$ apparaît partout ailleurs ${ }^{43}$. Il est tout aussi significatif que les « royaumes " de la péninsule Thaï-Malaise n'envoient pas leur propre ambassade en Chine avant le $v^{c}$ siècle ${ }^{+4}$. On peut supposer qu'une relation de type tributaire liait le Funan (convoitant, outre un accès direct au golfe du Bengale, l'or et l'étain de la péninsule) à ce que les auteurs chinois désignaient alors comme des «territoires vassaux » ayant tous «leurs propres chefs ${ }^{45}$.

La seconde hypothèse - celle d'un choix du Funan de ne pas emprunter à l'Inde - est tout autant à écarter puisqu'elle ignore les témoins d'une indianisation antérieurs au $\aleph^{\circ}$ siècle, à commencer par les linga et le tracé géométrique de Óc Eo. Il est utile néanmoins de dire quelques mots de la façon dont les sources chinoises ont pu être mobilisées à l'appui de cette hypothèse.

Le mythe de fondation du Funan a été beaucoup cité de ce point de vue. Rappelons brièvement les grandes lignes de ce récit transmis par les auteurs chinois. Le Funan avait initialement pour souverain une femme appelée Liuye. Un étranger, Huntian ${ }^{46}$, rêva qu'un " génie » lui donnait un arc et lui ordonnait de s’embarquer sur un navire. Le

41. Certains des « royaumes » non nommés ont dû correspondre aux contrées mentionnées dans les sources indiennes ou les écrits chinois traitant des périodes légèrement plus tardives (Wheatley 1961 : 287). Tel est le cas par exemple de Tāmbralinga, du Langkasuka ou encore de Panpan.

42. Une telle mesure est supposée correspondre à un trajet effectué le long des côtes du golfe du Siam. Un li devait couvrir environ 360 mètres. Rappelons toutefois que ces mesures demeurent difficiles à interpréter et nous livrent surtout des ordres de grandeur.

43. Cf. le Nanqishu, le Jinshu, le Liangshu (dans les premières lignes de son article consacré au Funan) et le Funan Chi (Pelliot 1903).

44. Ambassades du Panpan à partir de 424 et du Langkasuka à partir de 515 (Wheatley 1961 : 48-49. 253-258). Aucune ambassade des trois guo nommés dans le récit de la conquête de Fan(shi)man n "est connue.

45. Ct. le Vamzhou Yiwuzhi (daté du uI" s.). dont un extrait est conservé dans le Taiping Yulan : " the rassal territories all have their own chiefs" (trad. Wheatley 1983:142) ou "les régions vassales ont toutes leurs mandarins ") (trad. Pelliot 1903:281).

46. Des différentes orthographes du nom attestées par les textes chinois. nous retenons ici celle privilégiée par Pelliot (190)3: 291 ). 
songe se réalisa et Huntian arriva au Funan. Dans un bref affrontement, Liuye prit peur et se soumit à lui. Huntian la prit alors pour femme et s'empara du royaume ${ }^{47}$. Paul Pelliot avait proposé, sous toute réserve, d'identifier Huntian au brahmane Kaunḍinya (cité, nous l'avons vu, dans une version plus tardive du récit), et le culte que celui-ci rend au "génie » lui apparaissant en rêve à un culte brahmanique ${ }^{48}$. Les auteurs plus récents, à commencer par Éveline Porée-Maspéro, se sont vivement opposés à cette lecture jugée indo-centrique. Estimant la restitution de Huntian en Kaundinya spéculative, ils ont privilégié un rapprochement avec les cultes des dieux du sol ou des ancêtres documentés par l'ethnologie sud-est asiatique ${ }^{+4}$.

Les titres des premiers souverains du Funan ont également retenu l'attention. De George Coedès à Michael Vickery, et à l'exception récente de Michel Ferlus ${ }^{50}$, la littérature s'est accordée sur l'hypothèse d'une titulature royale dépourvue de tout caractère indianisé. S'appuyant sur l'interprétation du terme même de fiınan, George Cœdès avait proposé de restituer une titulature khmère qui aurait désigné les souverains funanais comme les « rois de la montagne " (vieux khmer : kuruni vnam). Cependant, l'hypothèse est particulièrement fragile puisque ni les inscriptions plus tardives, ni les textes chinois ne rapportent l'existence d'une telle titulature (en khmer ou transcrite du khmer). Michael Vickery note, en revanche, que les unes parlent de poñ et les autres de fan, ce qui l'a conduit à proposer une correspondance entre les deux termes $(1998: 203)$. L'hypothèse n'est guère plus assurée que celle de Coedès. Comme le concède lui-même Michael Vickery, la restitution de poñ à partir de fan est loin d'être parfaite, et on ne peut exclure que fan ait désigné non pas un titre mais un ethnonyme (ibid., p. 67).

Ce qui subsiste de ces hypothèses mal assurées, qui butent sur la pauvreté des sources, est le constat d'une absence. De fait, les données des textes chinois, qui sont nos seules sources écrites disponibles pour la période (les sceaux inscrits mis à part), n'apportent pas la preuve du caractère indianisé des titres et des noms portés par les premiers souverains funanais (ceux des $\|$ "III siècles). La même remarque paraît s'appliquer aussi au mythe de fondation. Mais l'argumentation a silentio ne montre pas grand-chose en soi. Que l'on se reporte un millénaire plus tard dans l'histoire du Cambodge ancien, et c'est dans une lointaine version de notre légende, si elle était considérée de la même façon isolément,

47. D'après les Jinshu. Nanqishu. Nan Shih. Liangshu et le Wushi waiguo zhuan cité dans le Taiping Yulan (trad. Pelliot 1903 et 1925 ).

48. Voir notamment le Wushi waiguo zhucm (relation sur les royaumes étrangers à l'époque du royaume de Wu, ouvrage cité dans le Taiping Yulcm et identifié au texte même de Kang Tai, l'envoyé chinois qui se rendit au Funan au sI" siècle de notre ère) : "II y eut un homme du pays de Mo-fou appelé Houenchen, qui aimait à rendre un culte à un génie, sans que son ardeur se relâchât jamais. Le génie füt touché de son extrême piété (...). Au matin. Houen-chen pénétra dans le temple et au pied de l'arbre du génie il trouva un arc " (trad. Pelliot $1925: 245-246$ ).

49. Poréc-Maspéro $1969: 795$. L’auteur se réfëre notamment au culte khmer des neak tes.

50. Michel ferlus propose de restituer derrière le titre fam, porté par les premiers souverains du funan selon les textes chinois. le sanskrit hrohmo ou hrähmant. L’hypothèse avait déjà été envisagée par Pelliot sans grande conviction. Ferlus y revient avec une argumentation de phonétique historique : antérieurement à l'effacement de la médiale - $r$ - aux alentours du $\mathrm{N}^{\mathrm{N}}$ siècle. le caractère fún permettait de transcrire tout à fait correctement le sanskrit hrahma/hröhmand (Ferlus 2005: 4-5). Que le terme brahmane ait pu ainsi entrer dans la titulature des premiers roi du Funan souleve de nombreuses interrogations. Mais e’est la démarche en soi qui nous semble d’abord faire difficulté. Que le caractère fun transcrive de façon satisfaisante les brahma/brähmang ne nous dit rien sur les autres correspondances éventuelles avec des termes en vieux khmer et les raisons pour lesquelles il faudrait alors privilégier l'hypothèse de Ferlus. 
que l'on pourrait avoir quelque peine à reconnaître les signes d'une société indianisée. On songe ici au récit de Zhou Daguan relatant l'union du souverain angkorien avec une femme-serpent. génie " maître du sol »" ". Personne ne contestera pourtant la dimension indianisée du Cambodge de la fin du XIII" siècle. Certes, les travaux sont nombreux à citer le récit de Zhou Daguan, pour mettre en doute la pertinence du concept même d'indianisation. Il s'agit alors de s'interroger sur la nature des pratiques que recouvre ce terme, mais il est difficilement possible d'ignorer, pour le Cambodge de cette époque, l'origine indienne, aussi lointaine soit-elle, de ces mêmes pratiques.

En d'autres termes, l'absence de traits indianisés dans un cas précis n'invalide pas l'hypothèse d'une indianisation, tandis que celle-ci peut difficilement être niée si ces mêmes traits existent par ailleurs. Cela ne veut pas dire que l'on ne doit pas s'efforcer de rendre compte d'une telle absence. Nous avons vu qu'environ deux siècles après l'ambassade chinoise qui rapporte la première le récit de Huntian et Liuye, une nouvelle version du mythe de fondation funanais fait désormais intervenir le brahmane Kauṇ̣inya. Les rois du Funan mentionnés dans les sources chinoises à la suite de cette légende portent alors un nom sanskrit dont la terminaison en -varman demeurera, par la suite, un attribut de l'ensemble des souverains du Cambodge ancien. Ce contraste entre le début du $I^{\circ}{ }^{\circ}$ siècle et la fin du IV" suggère un état différent de l'indianisation du Funan à deux moments distincts de son histoire. Il n'y a là rien de très surprenant et l'on se souviendra à ce sujet du passage du Liangshu invitant à distinguer différentes étapes dans l'indianisation de la région : ayant été proclamé roi par les gens du Funan. le brahmane Kaundunya, nous dit le texte, "changea encore toutes les règles selon les méthodes de l'Inde "). Il est vrai que l'historiographie récente a interprété ce passage comme le produit d'un effort de rationalisation de l'histoire funanaise par les auteurs chinois ${ }^{52}$. A l'inverse, les auteurs du début du siècle dernier y ont vu un témoignage précieux des vagues successives d'indianisation à l'initiative des acteurs du sous-continent. L’image diffusionniste de « vagues successives », fortement teintée du colonialisme de l'époque, est évidemment à rejeter, mais les grandes lignes de la chronologie qui lui est associée demeurent valides à nos yeux.

Nous ferons, cependant, une dernière observation sur cette absence apparente de traits indianisés dans le Funan des $\| I^{\circ}-1 I^{\circ}$ siècles. Dire que l'on a affaire là à un premier état de l'indianisation de la région ne nous engage pas à grand-chose et signifie simplement, et de façon assez vague, que certains choix d'emprunts à l'Inde n'ont pas été faits par le Funan des débuts, tandis qu'ils le seront 150 ans ou 200 ans plus tard. Il n'est pas sûr que ce type d'observations, quand bien même on serait en mesure d'être plus précis, puisse suffire à rendre compte de l'évolution de l'indianisation du Funan. Car si les choix du

51. «Pour ce qui est de la Tour d'or à l'intérieur du palais, le souverain va coucher la nuit à son sommet. Tous les indigènes prétendent que dans la tour il y a un génie qui est un serpent à neuf têtes, maître du sol de tout le royaume. Ce génie apparaît toutes les nuits sous la forme d'une femme. C'est avec lui que le souverain couche d'abord et s'unit. Même les épouses du roi n'oseraient entrer. Le roi sort à la deuxième veille, et peut alors dormir avec ses épouses et ses concubines " (trad. Pelliot 1951 [1997] : 12).

52. Citant l'extrait du Liangshu, Vickery fait suivre d’un sic le terme "encore » (Vickery 1998). L'auteur se rallie alors à la position d'Anthony Christie, qui voit dans ce récit le produit d'une dittographic chinoise (Christie 1979: 287): les royaumes sud-est asiatiques ne commenceraient vraiment à adopter les pratiques et les croyances du monde indien qu à partir de la fin du IN" siècle Pour un examen critique du traitement réservé aux sources chinoises dans l’historiographie récente. voir Bourdonneau 2003a. 
Funan ne furent probablement pas les mêmes d'un siècle à l'autre, disons brièvement que ce qu'il y avait à choisir (en Inde) ne l'était pas non plus. Nous songeons à la place changeante du sanskrit, en particulier dans sa relation au pouvoir, et aux réflexions que Sheldon Pollock a consacrées à cette évolution qui se déroule en Inde durant les cinq premiers siècles de notre ère. En Inde, souligne Pollock, ce n'est que tardivement et de façon progressive, à partir du $\mathrm{II}^{\mathrm{e}}$ siècle de notre ère et, de façon plus nette, à partir des III" et IV siècles, que se développe l'usage du sanskrit, instrument d'une nouvelle forme d'expression du pouvoir politique (2007: 73). Jusque-là, le recours au sanskrit était demeuré limité au domaine de la liturgie. Pollock prend pour exemple les pratiques culturelles des Sātavāhana et des premiers Pallava. Les souverains sātavāhana dominèrent une large partie de l'Inde méridionale entre le milieu du $\mathrm{II}^{\mathrm{e}}$ siècle avant notre ère et le milieu du ${ } \mathrm{II}^{ }$siècle de notre ère. Les nombreux témoignages écrits qu'ils ont laissés montrent sans ambiguïté qu'ils se percevaient comme les représentants d'une culture brahmanique et vaidika. Or, aucun des textes non liturgiques qui nous sont parvenus n'est en sanskrit (ibid., p. 61). Dans le Nord du Tamil Nadu, à la fin du III $^{\mathrm{e}}$ siècle et au début du $I V^{e}$, les premières inscriptions des Pallava (300-900) sont également instructives. Pollock donne ainsi deux exemples d'inscriptions sur plaque de cuivre relatant des donations de terre par un souverain. Ces documents sont rédigés en prakrit mais, de façon remarquable, la légende portée sur les sceaux qui les accompagnent livre le nom du roi sous une forme sanskrite dont l'orthographe diffère de celle lue sur les plaques de cuivre ${ }^{53}$. De ces exemples indiens, nous retiendrons que l'utilisation du sanskrit est une chose, l'indianisation en est une autre.

\section{La fouille de l'enceinte (pl. 8)}

Il nous reste à verser une dernière pièce au dossier sur l'ancienneté de Óc Eo. Dans le cadre de la mission franco-vietnamienne "Archéologie du delta du Mékong " menée à Óc Eo entre 1997 et 2002, nous avons réalisé une tranchée d'une longueur totale de $24 \mathrm{~m}$, sur le côté ouest de l'enceinte, à $680 \mathrm{~m}$ au nord-ouest du tertre gò Óc Eo. Rien ne signalant plus aujourd'hui l'existence en surface de l'enceinte, la localisation s'est faite par GPS, d'après les anciennes photographies aériennes géoréférencées. La tranchée a été implantée perpendiculairement à la douve intérieure de l'enceinte, ou ce qui peut être défini plus précisément comme la douve pourtournante du carroyage intérieur de la ville. Il s'agit de la douve qui apparaît sur les photographies aériennes comme la plus large (sa trace mesure environ $30 \mathrm{~m}$ à l'emplacement du sondage).

La stratigraphie du site peut se résumer de la façon suivante. Les carottages réalisés à l'emplacement de la fouille ont permis de localiser à une profondeur de $3 \mathrm{~m}$ sous la surface la limite supérieure du remaniement du substrat pléistocène ${ }^{54}$. Lui succède une phase d'accrétion sédimentaire qui voit l'élévation progressive du niveau de la plaine sans intervention anthropique jusqu'à $1 \mathrm{~m}$ sous la surface actuelle. Comme ailleurs dans Ic delta, correspond à cette phase une argile plastique, caractérisée par la présence de lits sableux et de matières organiques millimétriques. De teinte grise en fond de sondage,

53. Pollock $2007: 63$. L'une des deux plaques de cuivre mentionne également un titre porté par le souverain et célébrant l'accomplissement de rites védicues par celui-ci. Or ce titre est, lui aussi, donné en prakrit. Seule la bénédiction en fin d’inscription est en sanskrit.

54. Les carottages ont élé réalisés par Lê Xuân Thuyên (Institut de recherche pour le développement du delta du Mékong, à Hô Chi Minh-Ville), Claude Vella (CEREGE-CNRS, UMR 6635. université Aix-Marseille I) et Catherine Stevens (Département de géographie de l'université de Liège). Voir Manguin $2002: 14-15$. 
cette argile prend une teinte jaune-ocre et un aspect compact au-dessus de l'altitude $0 \mathrm{~m}$ à l'extrémité Est du sondage (immédiatement à l'est du fond de la douve, cf. infica). Sur lc reste de la tranchée, la partic supéricure de l’argile plastique montre également des taches d'oxydation, en particulier à proximité du fond de la douve.

Le fond de la douve est à un peu plus de $2 \mathrm{~m}$ sous la surface actuelle, à une altitude de $0,20 \mathrm{~m}$. On est ici à peine $1 \mathrm{~m}$ plus bas que le niveau ancien de la plaine tel que l'on peut l'observer sur la partie ouest du sondage; à cette altitude, la douve ne mesure qu'entre $1,50 \mathrm{~m}$ et $2 \mathrm{~m}$ de large. Si côté ouest, son profil remonte assez rapidement, côté est, il est d'abord marqué par une "marche » de $50 \mathrm{~cm}$ de haut, puis remonte progressivement : il est à $0,80 \mathrm{~m}(120 \mathrm{~cm}$ sous la surface $)$ à $5 \mathrm{~m}$ du fond de la douve, et à environ $1,60 \mathrm{~m}$ (40 cm sous la surface actuelle) à $13 \mathrm{~m}$ du fond de la douve selon un carottage réalisé à l'est de notre sondage ${ }^{55}$. La douve a été creusée en déposant les déblais côté est, c'està-dire côté intérieur de l'enceinte ${ }^{56}$. La teinte ocre-jaune s'explique par l'oxydation de la berge du canal soumis au battement du niveau de l'eau dans la douve et à celui de la nappe d'inondation.

Le sommet de la berge a pu être à l'origine plus élevé, si l'on considère son érosion naturelle et surtout la mise en culture récente de la plaine qui a pu en partie l'araser. Toutefois, antérieurement à cette mise en culture, Malleret ne signale pas d'ondulation significative du terrain qui correspondrait sans ambiguïté aux tracés de l'enceinte. Par ailleurs, une altitude de $1,60 \mathrm{~m}$, soit $60-70 \mathrm{~cm}$ au-dessus du niveau ancien de la plaine et $1,80 \mathrm{~m}$ plus haut que le fond de la douve, correspondrait assez bien au volume de terre qu'il a fallu déblayer pour atteindre la profondeur observée en coupe.

Des traces d'activités se signalent par la présence d'artefacts qui, sans être abondants, sont suffisamment représentés pour permettre de restituer, sans surprise, la présence d'un habitat à proximité : matériel céramique, fragments de briques, scories. Seul un trou de poteau a été mis en évidence (qui ne saurait bien sûr suffire pour supposer l'existence d'une palissade associée à la douve).

Le fond de la douve se signale par une couche d'argile riche en morceaux de charbon, d'environ $20 \mathrm{~cm}$ d'épaisseur (UF07). Au-dessus, le colmatage de la douve se poursuit sans que l'on puisse aisément faire la différence entre le faciès de ce colmatage et celui de la sédimentation de la plaine qui s'exhausse progressivement. La dernière phase de la stratigraphie du site correspond à la mise en valeur agricole de la plaine à époque récente, marquée par une couche arable plus épaisse dans la partie est de notre tranchée, c'est-à-dire précisément là où la douve a été creusée.

Trois charbons provenant de la couche en fond de douve (UF07) ont été prélevés pour datation au $\mathrm{C}^{14}$. Les résultats obtenus sont les suivants : $1882 \pm 47 \mathrm{BP}, 1934 \pm 48 \mathrm{BP}$, $1939 \pm 47 \mathrm{BP}^{57}$. Soit, respectivement, avec une erreur à 2 sigma, les datations calibrées

55. Sur le relevé de la coupe, l’UF05 correspond à des remaniements de la surface de la berge, qui ont pu intervenir dès son creusement.

56. À l'ouest, à distance de notre sondage, d'autres carottages révèlent la présence d'un même niveau oxydé proche de la surface, suggérant de la même façon une levée de terre; on peut raisonnablement supposer que cette levée est issue du creusement de la seconde douve située plus à l'ouest. La distance qu'il faut alors restituer entre le fond des deux premières douves reste cohérente avec ce que l'on observe sur les photographies aériennes, soit une distance de 35 à $40 \mathrm{~m}$.

57. Ces datations, comme toutes celles de la mission. ont été effectuées au laboratoire de l'université de Waikato, en Nouvelle-Zélande. Elles portent respectivement les numéros WK13750. WK 13749. WK13751. 
suivantes : 20-250 de notre ère; 50 avant notre ère-220 de notre ère; (à nouveau) 50 avant notre ère-220 de notre ère. Ces datations invitent à leur tour à dater l'enceinte, et donc le tracé géométrique de la ville de Óc Eo, des trois premiers siècles de notre ère. On sait, toutefois, la prudence qui s'impose dans l'utilisation des datations au radiocarbone. Elles ne viennent pas apporter le fond d'objectivité qui manquerait à l'analyse stylistique ou paléographique des linga ou des sceaux inscrits. Elles peuvent être, on le sait, tout aussi aisément manipulables. Les charbons de bois sont, de manière générale, d'une représentativité "moyenne " pour les événements archéologiques que l'on cherche à dater.

Si nos datations nous paraissent militer en faveur d'une fondation de la ville antérieurement au IV siècle, il importe donc de préciser comment. Il est a priori toujours possible qu'un charbon de bois donné provienne des cernes plus anciennes d'un arbre, auquel cas "l'événement radiocarbone " peut être nettement antérieur à celui du brûlage du bois, ce qui aboutirait à vieillir notre enceinte. On voit, cependant, qu'il faudrait ici un écart assez conséquent, d'au minimum 50 à 80 ans, pour qu'on puisse soutenir l'hypothèse d'une enceinte postérieure au $\Pi^{\mathrm{e}} \mathrm{siècle}^{58}$. On opposera également à ce type d'objections deux autres remarques, dans l'ordre suivant. II s'agit, avant tout, d'attirer l'attention sur la remarquable cohérence interne des datations obtenues, les trois charbons ayant livré sensiblement la même fourchette chronologique ${ }^{59}$. On soulignera, ensuite, leur cohérence externe. Il s'agit, là encore, de considérer globalement le corpus de données disponibles. Nos datations au radiocarbone s'accordent, d'une part, avec les datations du même type obtenues ailleurs sur le site (à partir de bois de pilotis ou de dépôts de suie; Bourdonneau \& Manguin 2000) et, d'autre part, comme nous l'avons vu, avec celles suggérées par l'analyse des autres témoins d'une indianisation (à savoir les linga ou les sceaux). Si nécessaire, on insistera sur l'ordre hiérarchique de ces deux types d'observations. Nous nous défendons de mener là un raisonnement circulaire. Pris de façon isolée, chaque type de sources passé ici en revue invite déjà clairement à privilégier l'hypothèse d'une indianisation aux $11^{\circ}-111^{\circ}$ siècles, mais sans être alors en mesure d'exclure l'hypothèse inverse (une datation basse, postérieure au IV siècle); prises ensemble, non seulement les sources suggèrent de privilégier la thèse de l'ancienneté du tracé de Óc Eo, mais elles autorisent désormais à exclure la seconde hypothèse ${ }^{60}$.

\section{Un « urbanisme angkorien »}

Dans ses grandes lignes, la chronologie qui avait été retenue par Malleret demeure valide. Elle proposait de situer un premier développement du Funan et de la ville de Óc Eo aux $\|^{\circ}$ et $\|^{\circ}$ siècles de notre ère. Nous pouvons aujourd'hui être plus précis et soutenir que "l'urbanisme " géométrique de la ville remonte à ce premier essor.

58. Une étude anthracologique devra bien sûr être menée à bien pour que l'on puisse identifier la nature du bois à l"origine de ces charbons. Les premières analyses palynologiques menées sur le site par Bui Thi Mai Girard (CNRS/Valbonne, Laboratoire de palynologie du Centre d'études Préhistoire, Antiquité, Moyen Âge) suggèrent l'existence antérieurement à la fondation de Óc Fo d'une forêt de mangrove dominée par les rhizophoracées, laissant par la suite place à une végétation d’herbacées (Manguin $2002: 18-19$ ).

59. En d'autres termes, soutenir l'hypothèse d'un écart significatif entre nos "événements $\mathrm{C}^{1+4}$ " et notre "événement archéologique" implique non pas une mais trois hypothèses, soit supposer, pour chacun de nos trois charbons, que e'est la lomation des plus anciennes cernes parmi les plus vieux arbres existants qui aurait été datéc. $A$ l’inverse, il suffit que ee ne soit pas le cas pour un seul de nos charbons et l'hypothèse d'un vieillissement de notre enceinte ne tient pas.

60. En retour (mais dans un second temps), chacune des hypothèses émises isolément se trouve renforcéc. 
Il s’agit alors de rétablir la ville ancienne de Óc Eo à la place qui doit lui revenir dans l'histoire de la région. Définir Óc Eo comme la première Angkor du Cambodge ancien est ici un peu plus qu'une simple boutade (qui aurait sans doute. en soi. le mérite de rappeler l'importance d'une archéologie hors Angkor). La comparaison nous paraît instructive à double titre ou, si l'on veut, à double sens : de Óc Eo à Angkor, d'Angkor à Óc Eo.

\section{Angkor au pluriel}

Dans le sens Óc Eo-Angkor, la comparaison met en relief l'une des grandes spécificités du monde khmer ${ }^{(1)}$. Elle jette en effet d'emblée un pont entre la cité funanaise et Angkor Thom, entre la première et la dernière réalisation « urbanistique » du Cambodge ancien. Ce faisant, elle embrasse un millénaire d'histoire khmère, de sorte qu 'une telle parenté survolant les siècles paraît difficilement compréhensible s'il s`agissait de créations isolées.

Comparer Angkor et Óc Eo, c'est donc signifier la spécificité d'une histoire urbaine caractérisée par un "urbanisme " géométrique dont les grandes réalisations ponctuent les dix siècles qui séparent Óc Eo d’Angkor Thom. Nous en avons déjà cité quelques exemples, figurant parmi les plus connus: Wat Luong Kau, au pied de Vat Phu, dans la province laotienne de Champassak; la " ville sous le barav" », c'est-à-dire la Banteay Chhœu de Bernard Philippe Groslier, à proximité d'Angkor "2: Sambor Prei Kuk, dans la province de Kompong Thom, identifié avec la capitale préangkorienne du

61. De nombreux auteurs ont considéré que le site de Óc Eo et l'histoire du Funan relevaient de l'étude du monde malais ou môn et non de celle de lancien pays khmer. Les raisons sont, en partie, asse semblables à celles qui ont conduit à ignorer l' « urbanisme géométrique » de Óc Eo et à le définir comme un port de commerce tournant le dos à son arrière-pays. Pourtant, 1'hypothèse inverse nous semble pouvoir être soutenue avec une certaine assurance. Nous renvoyons sur ce point à l"opinion récemment exprimée par Michael Vickery (20)3-()4 : 125), nous contentant ici d'attirer l'attention sur une inscription comme la «stèle de Práh Kŭhã Lûon » (K. 44) retrouvée dans la province méridionale de Kampot : datée du troisième quart du vII siècle (sous le règne de Jayavarman I), elle relate une fondation qui nous renvoie au début du v゙ siècle (sous le règne du roi funanais Raudravarman/Rudravarman); tout, dans le récit de cette fondation. évoque le monde khmer, à commencer par la titulature des dignitaires et les noms des rivières et des étangs servant à délimiter le domaine donné au dieu (Códès $1942: 10-13$ ).

62. C'f. pl. 9. La ville en question est naturellement un bon candidat pour le fameux Purandarapura. possible capitale de Jayavarman $I^{\mathrm{er}}$, selon une hypothèse formulée initialement par Pierre Dupont ( 1955 : 97). Certes, Christophe Pottier a récemment proposé d’interpréter le réseau de canaux dessinant ce plan quadrillé (nommé CP807) comme faisant partie d'un système de distribution pour l'eau retenue dans le Baray occidental (Pottier 2000b : fig. 1 et 2). L'hypothèse repose toutefois sur une interprétation problématique des photographies aériennes. Signalons en particulier les points suivants : les redans se découpant sur la digue du haray ne correspondent pas aux canaux orientés nord-sud de Banteay Chhoeu; le canal CP504 rejoignant le côté sud de Banteay Chhoeu peut tout à fait être postérieur au réseau CP807 (et à la formation d'un méandre à son angle sud-est, formation qui s'accorde c priori assez mal avec la thèse d'une alimentation en eau contrôlée par un système de vannes), il ne saurait donc servir à dater la fondation de celui-ci; le canal CP709 ne peut être défini sans réserve comme un canal distributaire ainsi que le propose l'auteur car, sur les photographies aériennes. il recoupe CP504: on observe à l'angle sud-est du baral au moins trois redans semblables à ceux de l'angle sud-ouest. Signalons, par ailleurs, deux coïncidences troublantes qui, à nos yeux. viennent conforter l'hypothèse d'un tracé urbain à Banteay Chhoeu (dont les dimensions apparaissent sensiblement identiques à celles du carroyage interne d Angkor Thom) : sur les couvertures aériennes et satellitaires du barca au moment des plus basses eaux, on observe asse z clairement une ancienne voie d eau venant rejoindre l'emplacement supposé de l'angle nord-est de la ville. et deux traces sombres viennent s'aligner assez. précisément avec le carroyage visible au sud de la digue. 
début du $\mathrm{VII}^{\mathfrak{e}}$ siècle; Banteay Prei Nokor, dans la province de Kompong Cham, correspondant sans doute à la fameuse Indrapura de l'épigraphie; Muang Singh et ses sept enceintes concentriques, dans la province de Kanchanaburi (en Thaïlande). S'y ajoutent de nombreux autres exemples, de dimensions assez variables. Les environs immédiats d'Angkor en comptent plusieurs, notamment au pied du Phnom Bok ou encore au sudouest du temple de Chau Srei Vibol (en bord du stung Roluos; Pottier 1999, carte 11). En s'éloignant d'Angkor, nous retrouvons d'autres sites importants distribués le long des anciens axes de communication : ainsi la large douve de Phnom Sruk, dans la province de Banteay Mean Chey, est implantée à proximité immédiate d'une chaussée qui rejoignait la capitale angkorienne située à $70 \mathrm{~km}$ vers le Sud-Est (Aymonier $1901: 348)^{63}$. Dans les provinces périphériques, signalons les deux exemples suivants illustrant, à leur tour, la vaste distribution géographique de ce type de site : dans la province de Takeo, non loin de la frontière avec le Vietnam, le Phnom Bayang présente sur son flanc nord une enceinte carrée, nommée Banteay Angkor, placée juste en bordure de la plaine d'inondation (Aymonier $1900: 163$ ); excentrée dans la province de Ratanakiri, le site de Kompong Cham Kau est, de la même façon, délimité par une enceinte quadrangulaire d'environ $1 \mathrm{~km}$ de côté (Parmentier $1927: 230$ ).

La liste est loin d'être exhaustive et il faudrait y ajouter les sites pour lesquels il existe une forte présomption d'un tracé en échiquier qui demanderait, cependant, à être confirmée par des fouilles. C'est le cas, nous l'avons vu, des environs immédiats du Phnom Bakheng. Malleret a également attiré l'attention sur le cas de Prei Nokor, l'ancienne Saigon khmer, qui montre à l'observation aérienne « de grandes artères et des voies secondaires intersectées à angle droit " (Malleret 1959-1963, vol. III : 444, 449) ${ }^{64}$. Il faudrait, cnfin, évoquer la parenté entre ces tracés urbains et ceux de nombreux temples qui prennent parfois les dimensions de véritables villes (et l'on songe en priorité à Angkor Vat dont l'espace délimité par l'enceinte extérieure était subdivisé selon un plan en damier, visible en partie aujourd'hui).

\section{Angkor sans pareil et sans urbaniste}

Différentes raisons permettent d'expliquer pourquoi cette profonde spécificité du monde khmer a été progressivement perdue de vue. La focalisation des recherches sur Angkor, en soi bien compréhensible, l'explique en partie; l'absence de mise en perspective dont souffrent parfois ces travaux n'est pas sans laisser l'impression que l'histoire du site serait coupée de celle du reste du pays et se suffirait à elle-même.

La vision bipolaire de l'histoire urbaine de l'Asie du Sud-Est, pensée à la fois selon un rythme ternaire, y est également pour beaucoup. Elle est venue renforcer la thèse formulée dès les premiers travaux de Malleret d'un Funan tourné vers le large, à l'image de son port de commerce, et dont l'histoire serait, pour cela, scindée de celle du Cambodge. Ainsi s'explique, chez Groslier, l'omission de Óc Eo lorsque celui-ci dresse la liste des villes géométriques qui précèdent les réalisations angkoriennes.

La même vision bipolaire a conduit à assimiler sous la même étiquette - celle des «villes agraires » des réalisations d'époque et de style très différents. On peut admettre qu'il y ait quelque valeur heuristique à assimiler les anciennes villes khmères et javanaises pour mieux les opposer aux «villes marchandes » du monde des réseaux. Mais

63. Je remercie Chan Sovichetra pour avoir attirer mon attention sur ce site.

64. Voir aussi les observations de l’auteur sur le site de Dá Nồi dans Malleret 1959-1963, vol. I : $128,131$. 
il est heuristiquement au moins aussi légitime d'opposer les anciennes villes khmères aux créations javanaises. Enclore l'habitat à l'intérieur d'une enceinte quadrangulaire. signaler généralement celle-ci par une douve en eau. subdiviser à l'occasion l'espace intérieur par un ensemble de voies se croisant à angle droit, il y a là une manière propre au monde khmer de marquer le paysage des grandes lignes de l'organisation du cosmos. À bien y regarder, nous ne la retrouverons nulle part ailleurs en Asie du Sud-Est (ou en Inde) - que ce soit à Java, au Champa ou en Thaïlande centrale - avec la même évidence.

Seules font exception les cités plus tardives des royaumes bouddhiques du Nord de la Thaïlande et surtout de la Birmanie, elles aussi de plan quadrangulaire, enfermées dans des enceintes et rythmées par l'orthogonalité des voies. À bien des égards, comme nous l'avons dit plus haut. l'urbanisme de ces villes paraît même surpasser les réalisations du Cambodge ancien. On comprend ainsi les tentatives faites pour définir ensemble les cités birmanes et les cités khmères, et illustrer de cette façon tout ce qui les sépare des villes amorphes des régions còtières (ou même de Java). Mais, là encore, on ne perdra pas de vue tout ce qui distingue par ailleurs notre « urbanisme angkorien » des réalisations birmanes, si bien que l'on gagne à renverser, une nouvelle fois, les catégories typologiques habituelles.

Décrivant les capitales birmanes et s'exprimant, pourrait-on dire, depuis les côtes indonésiennes, Anthony Reid fait observer fort justement qu'elles livrent l'illustration la plus frappante en Asie du Sud-Est d'un concept d'espace urbain spécifique, défini par des murs défensifs et contrastant avec le pays alentour (1993:80-81). Venant s'ajouter à la position centrale du palais royal (au cœur géométrique de la cité), cette caractéristique constitue une différence majeure avec les villes khmères. De ce point de vue, ces dernières paraissent plus proches des exemples austronésiens. Les villes du Cambodge ancien ne se présentent pas, ou rarement, comme des espaces fortifiés ${ }^{65}$. L'exemple de Óc Eo, ou celui de Banteay Chhœu, le montre clairement. Si le creusement d'une ou de plusieurs douves permet de délimiter un espace, il ne va pas de soi qu'il instaure une coupure radicale dans le paysage opposant, à l'instar d'une fortification, l'intérieur à l'extérieur. Il est significatif que, dans plusieurs cas, l'enceinte ne se referme par sur elle-même, le quatrième côté de la ville étant formé par un cours d'eau. C'est le cas au moins à Sambor Prei Kuk, à Muang Singh et probablement au Wat Luong Kau ${ }^{66}$. Rappelons qu'à Óc Eo aussi, mais d'une façon différente, l'enceinte n'est pas véritablement refermée sur ellemême : la ville est traversée de part en part par un canal recoupant le tracé de son enceinte et la mettant en relation avec les rivières rejoignant la côte et le Bassac (Bourdonneau 2003b). Le fait que la ville soit aussi bien délimitée que traversée par l'eau constitue, là encore à la suite de Óc Eo, un thème récurrent de l'histoire urbaine du Cambodge.

La subdivision de l'espace urbain selon un carroyage géométrique instaure-t-elle davantage une opposition entre l'intérieur et l'extérieur de la ville? En d'autres termes,

65. Il n'est peut-être pas indifférent que les deux principales villes (et capitales) du Cambodge ancien à être dotées d'une enceinte dont la qualité de « fortification » n'est pas douteuse soient celles pour lesquelles on dispose de sources écrites évoquant précisément la crainte d'une conquête à un moment de leur histoire : Temu-Angkor Borei qui sera prise par le Zhenla : Yaśodharapura-Angkor Thom bâtie au lendemain de sa conquête par le Champa. Nous sommes tenté de voir là l'illustration a contrario que la fortification n’est pas intégrée à la tradition « urbanistique » du monde khmer mais vient en réponse à une menace précise.

66. À l'époque post-angkorienne, c’est le cas de Longvek/Lovêk (comme à Sambor Prei Kuk et au Wat Luong Kau. le cours d'eau délimite le côté est de la ville). Il va de soi que des considérations de géostratégie peuvent également rendre compte de ces implantations. 
l'existence d'une grille régulière induit-elle forcément un authentique urbanisme (un urbanisme aménageant "l'espace vécu», c'est-à-dire organisant la vie sociale via les formes prises par la ville)? Ne faut-il pas, tout au contraire, envisager que le plan en échiquier des anciennes villes khmères représente le degré zéro d'un tel urbanisme? En un sens, cela irait presque de soi. Une ville est d'autant moins une œuvre d'urbaniste qu'elle accorde fidèlement les grandes lignes de son tracé aux harmonies cosmiques. Une ville se conçoit d'autant moins comme « mésocosme », c'est-à-dire comme un espace doté d'un ordre qui lui est propre, à proportion qu'elle se donne les allures ordonnées du macrocosme.

Les principes dont procède l'organisation spatiale de la cité doivent être cherchés ailleurs. Dans le cas du Cambodge ancien, le peu que l'on en sait invite à regarder de l'autre côté de la douve. Non pas pour trouver un « mésocosme » villageois aussi improbable à époque ancienne qu'aux périodes plus récentes, mais pour y reconnaître un sens de l'espace commun à l'ensemble du territoire et dont le monde rural et la ville livreront une modalité différente.

Les indices livrés par l'archéologie et l'épigraphie s'accordent jusqu'à présent avec les observations de l'ethnologie pour définir l'habitat rural du monde khmer comme un habitat dispersé. Là même où une certaine forme de regroupement est attestée, c'est l'espacement entre les unités d'habitat qui retient encore l'attention, chaque maison gardant son individualité, entourée d'un jardin-verger, sur le modèle de l'îlot de terre avec l'eau à ses pieds en saison humide (Delvert $1994: 210$ ). Les quelques données à notre disposition laissent à penser que l'habitat urbain offrait également des caractéristiques assez proches. Les premières prospections réalisées à Óc $\mathrm{Eo}^{67}$, I'examen des photographies aériennes de sites comme Banteay Chhoeu ou Wat Luong Kau, suggèrent une assez faible densité d'occupation à l'intérieur même des enceintes. Parce qu'ils ont été en partie nivelés et font désormais place à la riziculture, il demeure néanmoins difficile de se prononcer de façon plus précise sur ces sites tant que des fouilles extensives n'y seront pas menées. Les sites qui ont conservé leur couvert forestier montrent naturellement une topographie plus mouvementée. C'est le cas à Angkor Thom, comme l'ont montré les récents travaux de prospections menés par Jacques Gaucher. À l'instar de ce que l'on observe autour du Phnom Bakheng, du Ta Keo et de Pre Rup, ou encore à Roluos (l'ancienne capitale Hariharālaya), l'alternance de zones de dépression et de points hauts évoque un mode d'occupation familier du Cambodge actuel, combinant tertres des habitations et bassinstrapeang ${ }^{68}$. Il est vrai que cette configuration offre, à Angkor Thom. un visage singulier. La planification cosmologique de la ville en $4 \times 4$ ou $8 \times 8$ carrés serait complétée par l'application d'une grille au maillage plus serré, basée sur un module rectangulaire de $361 \times 90 \mathrm{~m}$ (orienté est-euest), assez comparable à celle que l'on observe aujourd'hui à l'intéricur de l'enceinte d'Angkor Vat. De nombreuses dépressions interprétées comme des trapeang s'alignent le long des voies (est-ouest) de cette grille. Soucieux avant tout de justifier la qualification d'Angkor Thom comme une ville, Gaucher insiste sur le fait que l'urbanisation à l'intéricur de l'enceinte « ne semble pas s'être limitée à un regrou-

67. Flles ont consisté. jusqu’à présent. en l'examen aux basses eaux des berges des canaux modernes qui traversent à intervalles réguliers et de part en part la surface de l'ancienne ville.

68. (jaucher 2004 : fig. 17. Pour unc cartographic récente. hors $\Lambda$ ngkor Thom, de ces tertres et $/ 1$ apeang. voir Pottier 1999 et Greater Angkor Project 2003 : fig. 3. I)ans le sillage de Groslier, Fletcher formule à partir de ce eonstat et le relevé des tracés linéaires l'hypothèse contestable d’un « complexe urbain à faible densité "s sétendant sur près de $1000 \mathrm{~km}^{2}$ (ibicl.). 
pement dense d'habitations autour d'un centre mais s’être étendue jusqu'aux quatre angles du quadrilatère " (2003:52). Cette urbanisation, ajoute l'auteur, "ne montre pas une succession informelle d'espaces libres ou d'habitations ni une éventuelle agglomération de villages distribués de manière aléatoire » (ibid.). Qu'il n'y ait pas eu une "agglomération de villages ", chacun en conviendra aisément. Mais l'hypothèse d'une succession « informelle » d'habitations et d'espaces libres est-elle infondée? Sans aucun doute, si l'on considère les alignements de bassins que génère l'existence d'une telle grille au maillage serré. On comprend naturellement que c'est sur ce point que Gaucher souhaite attirer l'attention. Pour autant, ces alignements ne concernent qu'une partie des bassins cartographiés. Une autre partie, tout aussi importante, se distribue de façon plus aléatoire, si bien d'ailleurs que nombre de ces bassins chevauchent et recoupent le tracé théorique de la grille ${ }^{(1)}$. L'existence de ces nombreux bassins et leur distribution aléatoire ${ }^{71}$ évoquent asse\% bien les caractéristiques de l'habitat rural du Cambodge traditionnel : l'espacement entre les maisons. la présence de vergers entourant chacune d'entre elles et, bien sûr, la proximité de l'eau sous la forme de trapeang. De façon intéressante, ce ne sont pas là des caractéristiques du seul habitat dispersé. Elles valent également pour ce que l'on peut désigner, en reprenant la formule de Delvert, comme «l'habitat étiré », tout aussi caractéristique des campagnes cambodgiennes : sur des dizaines de kilomètres, les maisons s'alignent "en chapelet " le long des berges de rivières ou en bordure de canaux et de routes, les unes à côté des autres mais chacune toujours entourée de son verger (Delvert $1994: 214$ ). En d'autres termes, l'alignement ne suffit pas ici à intégrer I'habitat et la rue ou le canal en une seule forme. Les bassins alignés d'Angkor Thom sont donc susceptibles à leur tour d'alimenter I'homologie posée avec l'habitat rural.

Les deux caractéristiques évoquées ici, l'ajointement lâche entre les unités d'habitat et la " clôture » végétale autour de celles-ci, nous renvoient au thème des "cités-jardins » ou «cités vertes » de l'Asie du Sud-Est, de Chiang Mai (quand bien même celle-ci est emmurée) aux anciennes cités de l'archipel, juxtaposition de "compounds-kompong » aristocratiques, chacun entouré des groupes de maisons de leurs dépendants (Reid 1993 : $87)^{71}$.

Nous sommes également renvoyés aux réflexions de Bernard Philippe Groslier autour du concept de "cité hydraulique ". Celle-ci est identifiée au " pays khmer » lui-même, pensé comme un tout homogène : " non seulement nous devons poser ici Urbs $=$ Rus, mais en fait nous devrions dire qu'il n'y a pas de différenciation; il y a tout simplement comme le pensaient les Khmers la Surface d'en-bas » (Groslier $1974: 110$ ). Selon l'auteur, ce qui définit alors la " cité » est « la maîtrise du sol et non l'étendue des ouvrages urbains " (ibid., p. 108), et ce qui assure une telle maîtrise est la mise en conformité, à la fois sacrée et profane, du sol via la réalisation de grands travaux agricoles et la

69. Voir en particulier Gaucher $2003: 46$, fig. 2. Dans la partie de la ville prise pour exemple par Gaucher, la distribution des trapeang est telle que le tracé de la grille disparaît presque entièrement du plan.

70. La remarque vaudrait quand bien même les fouilles à venir montreraient que les dépressions repérées en surface ne sont pas toutes des bassins.

71. C"est ce thème de la "cité non urbaine » qui est également à l'origine des tentatives de comparaisons, plus ou moins heureuses, avec d'autres régions du monde tropical et, singulièrement, avec les cités maya de la Mésoamérique. (e type de démarche. illustrée il y a déjà cinquante ans par Michael Coe (1957). regagne en vigueur cés derniers temps, à la faveur de l’intérét accru porté à l’archéologie environnementale. Pour les villes du Cambodge post-angkorien. voir les brèves réflexions de Mak Phoeun (1991: 48) sur labsence de distinction nette entre le paysage urbain et les campagnes environnantes. 
reproduction d'une géographie sacrée. De ce point de vue, la « cité hydraulique » est un centre de pouvoir dont la capitale est l'archétype mais que l'on " retrouve en autant de projections locales jusque dans le temple et l'idole du plus petit village » (ibid., p. 110). Entre ces différents sièges du pouvoir, souligne Groslier, il y aurait une différence tout au plus quantitative, mais non qualitative.

C'est une thèse assez différente que nous défendrons ici. Groslier le soulignait luimême : la formulation du concept de «cité hydraulique » est paradoxale en ce sens que la démarche vise à montrer l'absence de cités khmères. Le propos de l'auteur glisse alors de la réflexion sur Angkor à celle sur le monde khmer. Ce n'est pas seulement à Angkor mais dans la tradition historique du Cambodge tout entière que le fait urbain serait une inconnue. Groslier nous donne ainsi l'impression d'avoir procédé à l'envers. L'attention portée aux vestiges monumentaux des baray et des temples l'a conduit à raisonner prioritairement sur les capitales d'Angkor, Hariharālaya et les « premières Yaśodharapura ", dépourvues d'une enceinte ou pour lesquelles l'existence d'une telle enceinte n'est pas prouvée. Ce faisant, Groslier définit le monde khmer à partir du fait angkorien - plus précisément, les deux ou trois siècles de l'histoire d'Angkor précédant les grands changements du XII' siècle - au lieu de faire l'inverse.

\section{Angkor comme lakkhana ou l'ordre au cour et sans contrainte}

L'enjeu est, à nos yeux, de réussir à penser en dehors de la typologie usuelle cette conception originale et, de fait, problématique d'une ville de plan géométrique mais sans réel urbanisme, enclose mais empreinte de ruralité. S'il est une solution à trouver, elle devrait venir d'une réflexion renouvelée sur la nature des relations sociales qui peuvent être associées au fait urbain dans le monde khmer. La tonalité assez fonctionnaliste des travaux menés sur le sujet y a peu aidé jusqu'à présent. Partant du constat que la cité khmère ne pouvait se définir comme un corps social distinct (sur le modèle des villes de l'antiquité classique ou du Moyen Âge occidental), Groslier ne concevait guère la possibilité d'une définition sociale de la ville, c'est-à-dire d'une « conscience de la ville » mise en acte par des pratiques distinctives. Ce qu'il lui substitue est une approche à laquelle est demeuré attaché le débat fameux sur la « cité hydraulique »: la ville comme le siège du pouvoir politique articulant l'infrastructure et la superstructure de la société (les ressources agricoles et les ressources spirituelles ou divines du pays). Il n'est pas sûr, cependant, que la thèse d'une telle articulation parvienne, au Cambodge comme ailleurs, à rendre compte des pratiques, urbaines et autres, qu'elle entend expliquer. Le problème ne vient pas de l'accent mis ici sur la dimension religieuse et/ou économique du fait urbain, mais du fait que le religieux et l'économique sont alors réifiés de sorte qu'ils paraissent contenir en eux-mêmes le principe de leur explication. Celle-ci est ainsi rapportée soit à un corpus de « croyances " composant un " substrat » culturel local, soit à une activité de production répondant à un déterminisme géographique. Utilisant les mêmes recettes, Groslier livre du village khmer sensiblement la même définition que pour la ville : un territoire sacré façonné par une communauté réunie autour du culte d'un esprit tutélaire, ancêtre-fondateur « maître du sol ». Ainsi seraient « structurées socialement » les campagnes du Cambodge et serait réhabilitée la notion de « village khmer », aussi malmenée que le concept de ville ${ }^{72}$. Les réserves exprimées ici tiennent au fait que les travaux de Groslier interrogent en réalité assez peu le contenu des relations sociales au sein d'une telle « communauté », ou entre celle-ci et ses « maîtres du sol ».

72. Dans le sillage de ces réflexions de Groslier sur le village khmer, voir également Ang Chouléan 1990. 
Si la présente étude n'est pas le lieu pour développer l'histoire sociale que nous appelons de nos voeux ou, disons, une « histoire culturelle du social » au sens défini par Roger (hartier (1998 [1989]: 73) - nous pouvons tout au moins signaler les approches existantes, susceptibles d'orienter les recherches dans cette direction.

Les travaux de Richard O'Connor, sur lesquels Wolters a déjà attiré l'attention. comptent parmi celles-là. Sa démarche se veut comparative et cherche à embrasser le fait urbain dans l'ensemble de l'Asie du Sud-Est, avec les avantages et inconvénients que cela comporte. L'intérêt pour nous est que la démonstration de l'auteur part du double constat qui nous semble s'appliquer au Cambodge : l'opposition traditionnelle entre «milieu rural » et « milieu urbain » recouvre de façon très imparfaite les données de l'observation: l'importance du fait urbain non seulement n'est pas douteuse, même si la littérature sur le sujet a parfois été tentée d'y voir un simple «produit d'importation », mais s`inscrit profondément dans la tradition historique de la région. O’Connor propose ainsi de substituer à la dichotomie usuelle rural/urbain une «dyade » ville/société construite comme une " opposition hiérarchique " au sens dumontien de l'expression : la ville occuperait, dans la relation d'opposition, une position de supériorité par le fait même qu'elle représente le tout ${ }^{73}$. Elle ne serait pas ici l'antithèse de la vie rurale, ni un « produit d'importation » surimposé à un substrat local, mais l'essence même de l'ordre social. Et c'est parce qu'elle serait cette essence de l'ordre qu'elle façonnerait à l'occasion son " urbanisme » sur les modèles cosmologiques empruntés au monde indien (R. O'Connor $1995: 30)$. L'appropriation de ces modèles, sommes-nous tenté d'ajouter, ne se ferait pas en niant l'altérité de ce qui est emprunté mais bien en conservant ou même en exacerbant cette altérité, et sans que cette conservation ne se fasse aux dépens de l'identité locale puisqu'au contraire, elle participe à la construction de celle-ci ${ }^{74}$.

Le recours à la notion d' "opposition hiérarchique " autorise. à nos yeux. ce que l'approche de Groslier laissait difficilement entrevoir : définir une « conscience de la ville » de type sud-est asiatique. Il est entendu que celle-ci a peu à voir avec la tradition occidentale et la ville comme "place publique $"{ }^{75}$. On conviendra également, avec Groslier ou bien d'autres, que la ville khmère, de planification cosmologique, est, par excellence, une fondation royale et, partant, le lieu d'une articulation entre le pouvoir politique et le sacré. Mais précisément : elle est fondamentalement le lieu de résidence de la ou des "Maisons royales », et de celles des Grands du royaume ${ }^{70}$. Comme l'écrit $\mathrm{R}$. O'Connor, la ville s'impose ainsi à la société comme un ensemble de distinctions de

73. Rappelons que l'opposition hiérarchique est définie par Louis Dumont (1979:400-403) comme une " relation entre l"ensemble et l"élément». Dans cette relation, ce qui est premier est l'ensemble et non pas les éléments pris isolément et venant s'empiler verticalement pour former une chaîne unique d'éléments de valeur croissante : "la totalité préexiste et il n'y a pas de substance ». La relation hiérarchique suppose la distinction de niveaux différents dans l'organisation de cette totalité. À un niveau supérieur, il y a unité, identité des catégories ou, plus précisément, englobement : une catégorie supérieure inclut la catégorie inférieure qui, réciproquement, l'exclut. À un niveau inféricur, les deux catégories sont différenciées dans une relation de complémentarité ou de contradiction. La singularité du principe hiérarchique tient à ce qu'il combine ces deux propositions de niveau différent : « la complémentarité ou contradiction est contenue dans une unité d'ordre supérieur ».

74. Nous développerons ectte thématique de l' «altérité incluse ». selon le mot de Florence Dupont (2005), dans un essai à venir sur l’indianisation.

75. Soit la ville comme liéu du politique où l" " on s"assemble pour donner forme à un parler-ensemble qui va dans le sens des intérêts du groupe " (Détienne 2000: 116).

76. Voir à ce sujet les remarques dans Népote \& Sisowath 1994:21 
statuts (et le statut renvoie ici forcément à la notion de royauté et d'ordre cosmique) : soit la ville comme le lieu d'unc urbanité déterminée par la proximité de la Maison royale. Si elle ne compose pas un "corps" social distinct du reste de la société, elle livre la représentation de ce qu'il y a de mieux en celle-ci et, partant, figure le tout de la société.

Cette approche de la ville demanderait naturellement à être étayée par une analyse plus serrée de la nature de cette urbanité et de ces distinctions de statuts évoquées par O'Connor (les réflexions anthropologiques menées par ailleurs sur la notion de " maison " pourraient se révéler précieuses à cet égard). Mais l'on devine le type d'analogie que l'on souhaite établir ici avec l'organisation spatiale de l'habitat dans le monde khmer : l"« urbanisme " géométrique des multiples Angkor nous semble bien entrer dans une relation de "dualisme hiérarchique " avec un habitat globalement dispersé.

Pris dans son ensemble, ce dernier se présente en effet comme un semis de maisons, chacune autonome au cœur d'un espace largement arboré. Leur distribution paraît se faire au hasard mais, comme l'illustrent les nombreuses prescriptions guidant l'implantation et la construction des maisons, ce n'est là qu'une apparence. L'espacement entre les maisons et la clôture végétale qui les accompagne n'apparaissent pas moins chargés de sens que les unités d'habitat elles-mêmes. Non seulement ils participent à la perception de celles-ci comme autant de microcosmes enclos, mais ils réfèrent directement ce microcosme domestique au macrocosme de la nature, soit la « surface d'en-bas » pensée comme un tout homogène où interagissent l'environnement, les esprits et les hommes (Népote 2003, 2004: Tainturier 2006). Si chaque maison est un " monde en soi », elle est donc intégrée à une trame naturelle qui joue un double rôle : elle est tout à la fois ce qui préserve l' "insularité » des habitations et ce qui les intègre dans une relation dynamique ${ }^{77}$. Ce sens de l'espace renvoie bien sûr à des pratiques concrètes et l'on se référera à ce sujet aux nombreuses observations des ethnologues invitant à définir le niveau vicinal du srok khmer comme "un tissu connectif" " ${ }^{7 x}$. Si donc la "surface d'en-bas ", entendue comme l'espace habité du monde khmer, se présente globalement comme un espace sans forme, celui-ci n'est pas sans ordre.

Considérons dès lors l'" urbanisme" géométrique du Cambodge ancien. Le tracé des enceintes urbaines, l'orthogonalité des voies ne s'opposent pas aux étendues environnantes comme l'introduction de l'ordre sur un fond de désordre. mais se conçoivent davantage comme la formalisation d'une trame qui ne s'offre pas autrement au regard. Formalisation doit s'entendre ici de deux façons : donner une forme à voir, mais aussi coordonner, harmoniser. La forme ne donne pas simplement une visibilité à la trame, elle en dégage les principes d'ordre. La distinction de la ville d'avec l'espace environnant et le reste de la société ne peut être, de ce point de vue, de nature simplement quantitative, comme l'écrivait (iroslier, ni véritablement qualitative. Elle est avant tout cette affaire de formes ou, disons, de signes. Dans le contexte du monde khmer, comme de manière générale dans le contexte sud-est asiatique, ce n’est pas là chose secondaire : l'exhibi-

77. On recomnaitra ici, par une sorte de retour de la comparaison, certaines des réflexions menés par Augustin Berclue sur la notion japonaise de me. ect espace transitionnel par lequel "l individuel embraye au collectif" ( (lateur évoque à ee sujet l’idé de " champ matriciel »). Berque rappelle alors le rapprochement que l'on peut établir, de ee point de vue, entre les villes japonaises et les villes sud-est asiatiques (Berque 1993: 34).

78. Nous empruntons lexpression "tissu connectif" à Fabienne l.uco (1998: 184). Voir également Forest 1992: Népote 1992 (chap).1), Ovesen. Trankell \& Öjendal 1996. 
tion de signes cosmiques (lakkhana) vaut pour lessence même du statut ainsi exhibé ${ }^{-"}$. ('e faisant, si la ville est bien affaire de formes ou de signes (et, partant. comme l'écrit () Connor. de "statuts"), on voit dans un même temps qu'elle ne saurait imposer (à proprement parler) un ordre. Livrant à la perception l'essence même de l'ordre ici-bas, son rôle n'est pas de l'instaurer. Le plan géométrique de la ville imprimerait d'ailleurs si peu sa mesure -.. y compris même à Angkor Thom, où son maillage est plus serré que l'habitat peut y demeurer empreint de "ruralité ». Ainsi peut-on comprendre les modalités d'application très variées de cet «urbanisme » géométrique. Délimitée par une ou plusieurs enceintes, celles-ci refermées sur elles-mêmes ou ouvertes sur un quatrième côté, éventuellement même sans enceinte (ainsi Hariharālaya), avec ou sans un carroyage interne. l'empreinte laissée par l' " urbanisme » des cités khmères est plus ou moins profonde. (ette manipulation des formes et la réalisation des haral et la construction de temples monumentaux y participent naturellement est alors fonction de la position qu'oceupe le pouvoir commanditaire dans le champ des rapports de force d'une époque donnée. C'est seulement de cette façon, suggérera-t-on, que l'on pourra expliquer des réalisations aussi différentes que les capitales de Hariharālaya-Roluos et de Yaśodharapura-Angkor Thom.

\section{Conclusion : Óc Eo, première Angkor et capitale funanaise}

Entre la cité ouverte d'Indravarman et la capitale fortifiée de Jayavarman VII, le modèle de référence demeure la ville de fondation royale, sans remparts mais avec une enceinte, celle-ci signalée par une douve et de plan quadrangulaire. Ainsi sommes-nous ramenés à Óc Eo et l'on peut désormais faire jouer en sa faveur la comparaison avec Angkor.

C"est suggérer, en particulier. que Óc Eo fut une fondation royale ayant rang de capitale. On peut mesurer la profonde influence de la thèse commerciale à ce fait précis qu'une telle hypothèse n'a que rarement été émise ${ }^{80}$. Dans une étude consacrée précisément aux anciennes capitales du Cambodge. Boisselier (1953) résume d'une phrase l'opinion générale qui écarte une telle possibilité sur le ton de l'évidence : «Go-Oc-Eo, la plus ancienne ville du Fou-nan actuellement reconnue, découverte par M. Louis Malleret, était un port et ne peut prétendre au titre de capitale malgré son importance ". Ce à quoi l'on répondra simplement qu'une ville peut être tournée vers les échanges sans que cela ne contredise son éventuel statut de capitale.

On rappellera, par ailleurs, tout ce qui milite ici en faveur d'une telle hypothèse. La parenté de Óc Eo avec les différentes "Angkor » postérieures est un élément d'autant plus significatif que Óc Eo est le seul site de l'histoire funanaise à offrir une telle similitude. L’ampleur de la ville, avec ses 300 hectares, est également à considérer. Óc Eo supporte assez bien, de ce point de vue, la comparaison avec des sites comme Sambor Prei Kuk, Angkor Borei ou Wat Luong Kau. Enfin, il y a à considérer le témoignage des auteurs chinois. Le Xin Tangshu rapporte que la conquête du Funan par le Zhenla dans le premier quart du VII" siècle entraîna le déplacement de la capitale funanaise, Temu,

79. Voir notamment (handler 1996:78: Népote \& Sisowath 1994:22. n. 20: Thierry 1985: 22, 270.

80. Malleret envisage très brièvement la possibilité d'une identification de Óc Eo à Nafuna. l'une des deux capitales funanaises mentionnés par les sources chinoises, mais l'on sait qu’il préfëre privilégier de loin la définition de Ó Eo comme une ville portuaire et marchande (Malleret 1959-1963, vol. III: 424). Nous avons émis une première fois l'hypothèse d une identification entre $O$ c Fo et Nafuna dans Bourdonncau 2003a. Flle apparait également dans Vo si Khai 2003:63-64. 
vers une ville située plus au sud, Nafuna. Pelliot a proposé de reconnaître dans ce dernier terme la transcription de navanagara, «ville neuve », tandis que Coedès a privilégié la restitution naravaranagara, la " ville du premier des hommes " ${ }^{\& 1}$. Quelle que soit l'hypothèse retenue, l'usage du terme sanskrit nagara retient l'attention : il désigne la "ville», mais aussi la « Ville» par excellence, la capitale ${ }^{\text {2 }}$. Les indications livrées par les sources chinoises suggèrent d'identifier Temu avec le site d'Angkor Borei (province de Takeo, Cambodge), et un certain consensus semble s'être imposé sur ce point parmi les historiens. Pour Nafuna, il n'est sans doute pas de meilleur candidat que le site d'Óc Eo, 80 kilomètres au sud d'Angkor Borei, les deux sites étant anciennement reliés par l'un des nombreux canaux qui sillonnaient le delta du Mékong ${ }^{83}$.

Si Óc Eo est bien Nafuna, les datations obtenues pour le site montrent que sa fondation était bien antérieure à la conquête par le Zhenla. Angkor Borei et Óc Eo ont pu être l'une et l'autre la capitale du Funan, à différents moments de son histoire ou même conjointement. Nous sommes assez enclins à privilégier cette seconde possibilité. L'hypothèse d'une double capitale funanaise évoque une configuration bien attestée par ailleurs dans l'histoire de l'Asie du Sud-Est continentale. La relation entre Óc Eo et Angkor Borei pourrait avoir été assez comparable à celle qui liait Ayutthaya et Lobpuri dans le courant du second millénaire et dans un autre delta de la région, celui de la Chao Phraya : la première fut une capitale fondée ex nihilo au centre d'une plaine d'inondation dominée par la culture du riz flottant, la seconde accueillait la cour lorsque Ayutthaya devenait trop inondée, le souverain et sa suite rejoignant alors Lobpuri en remontant à cette occasion le cours du fleuve qui reliait les deux capitales (De Choisy $2006: 148,191$ ). Une capitale méridionale en plein delta, une autre implantée au nord en zone exondéc, une voie navigable établissant une communication directe : ce sont là autant des éléments que l'on retrouve dans le delta du Mékong funanais. À l'époque post-angkorienne également, dès lors que la cour viendra s`implanter dans la région du delta, elle sera contrainte à une forme d'itinérance déterminée par le rythme des inondations. Óc Eo et Angkor Borei seraient ainsi dans une relation de complémentarité susceptible d'éclairer en partie le contraste très marqué de leur urbanisme. Formant une sorte de presqu'île en limite de la plaine d'inondation du delta, Angkor Borei est une ville de plan entièrement amorphe, en partie fortifiée, modelée par le cours sinueux de la rivière du même nom. Óc Eo, nous l'avons $\mathrm{vu}$, en est le pendant. Il est possible que le peu d'application des souverains funanais à modeler la topographie naturelle d'Angkor Borei fut à proportion inverse de l'attention portée à Óc Eo pour instituer un « urbanisme » géométrique sans concession.

81. Pelliot 1903: 295: Coedès 1943-1946:4. Le roi du funan «avait sa capitale à la ville de T”ö-mou. Brusquement sa ville a été réduite par le Téchen-la et il lui a fallu émigrer au Sud de la ville à Na-fou-na " (trad. Pelliot 1903:274).

82. L’épigraphie en vieux khmer utilise ainsi le terme nugera pour désigner Yaśodharapura. ćest-à-dire Angkor (dont la source étymologique, rappelons-le, est précisément nagara).

83. Pour une cartographie de ce canal, cf. Bourdonncau 2003b. 


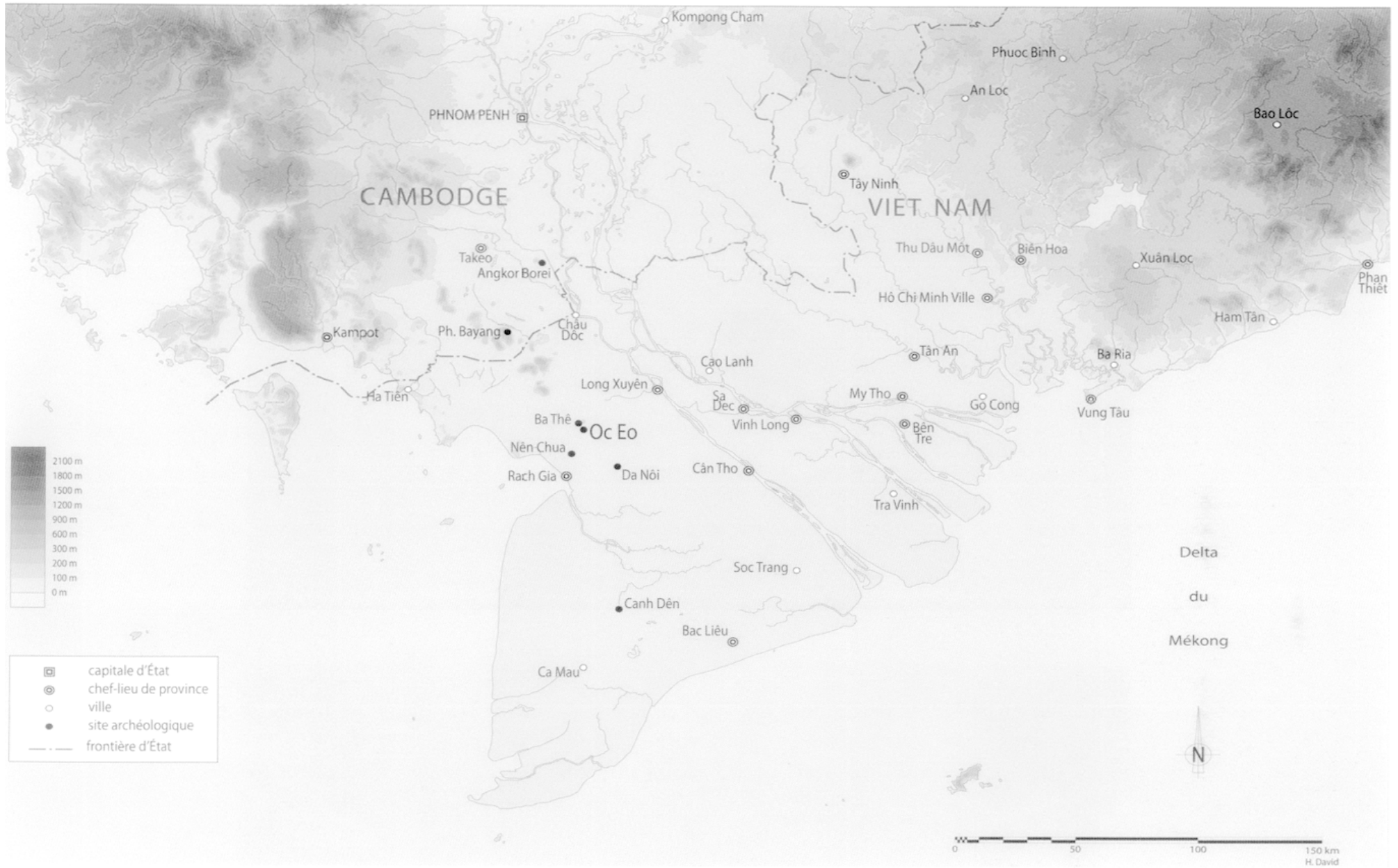

Pl. 1. ('arte du delta et localisation de Óc Eo (réalisation : Hélène David). 
PI. 2
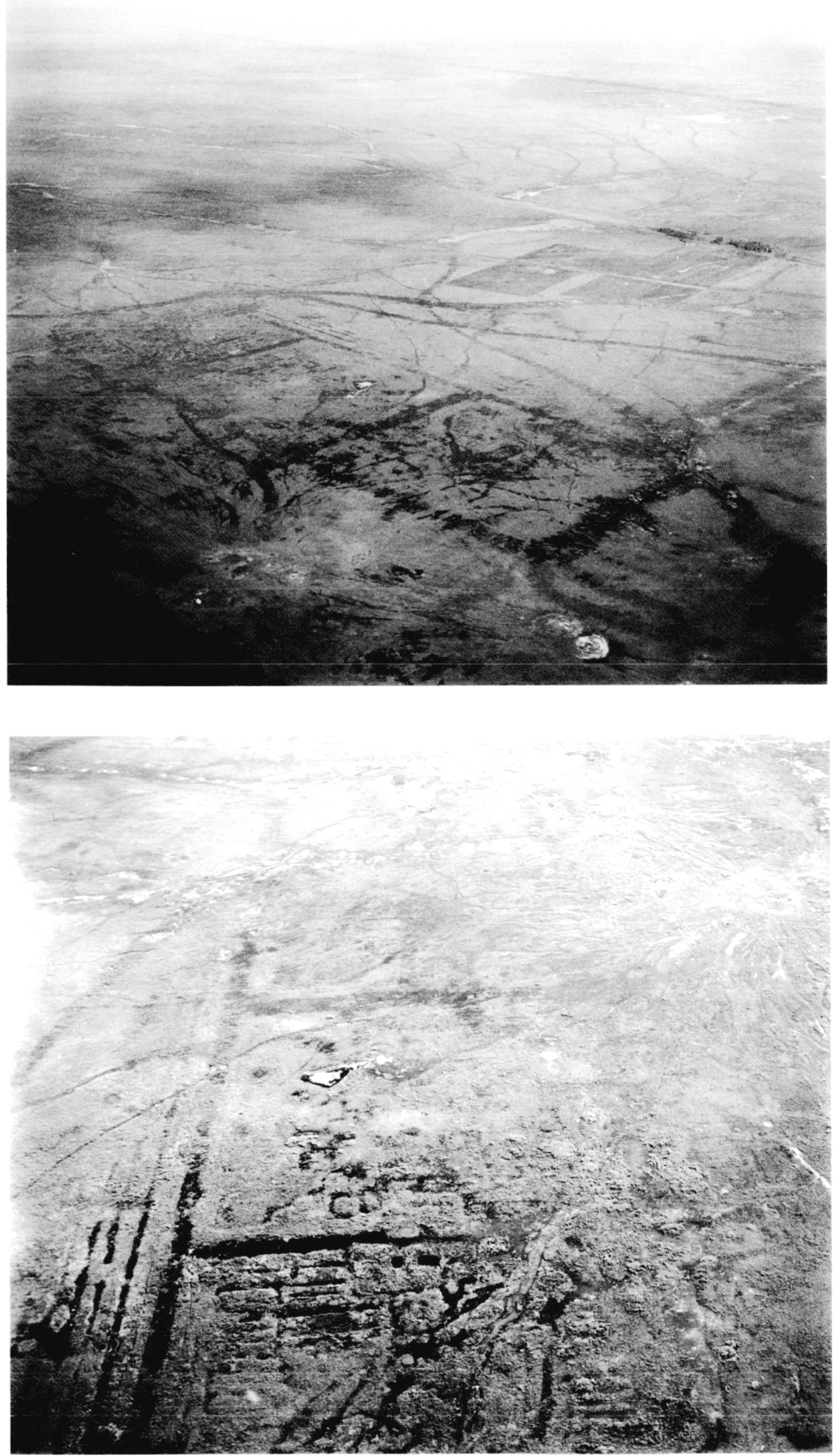

PI. 3 


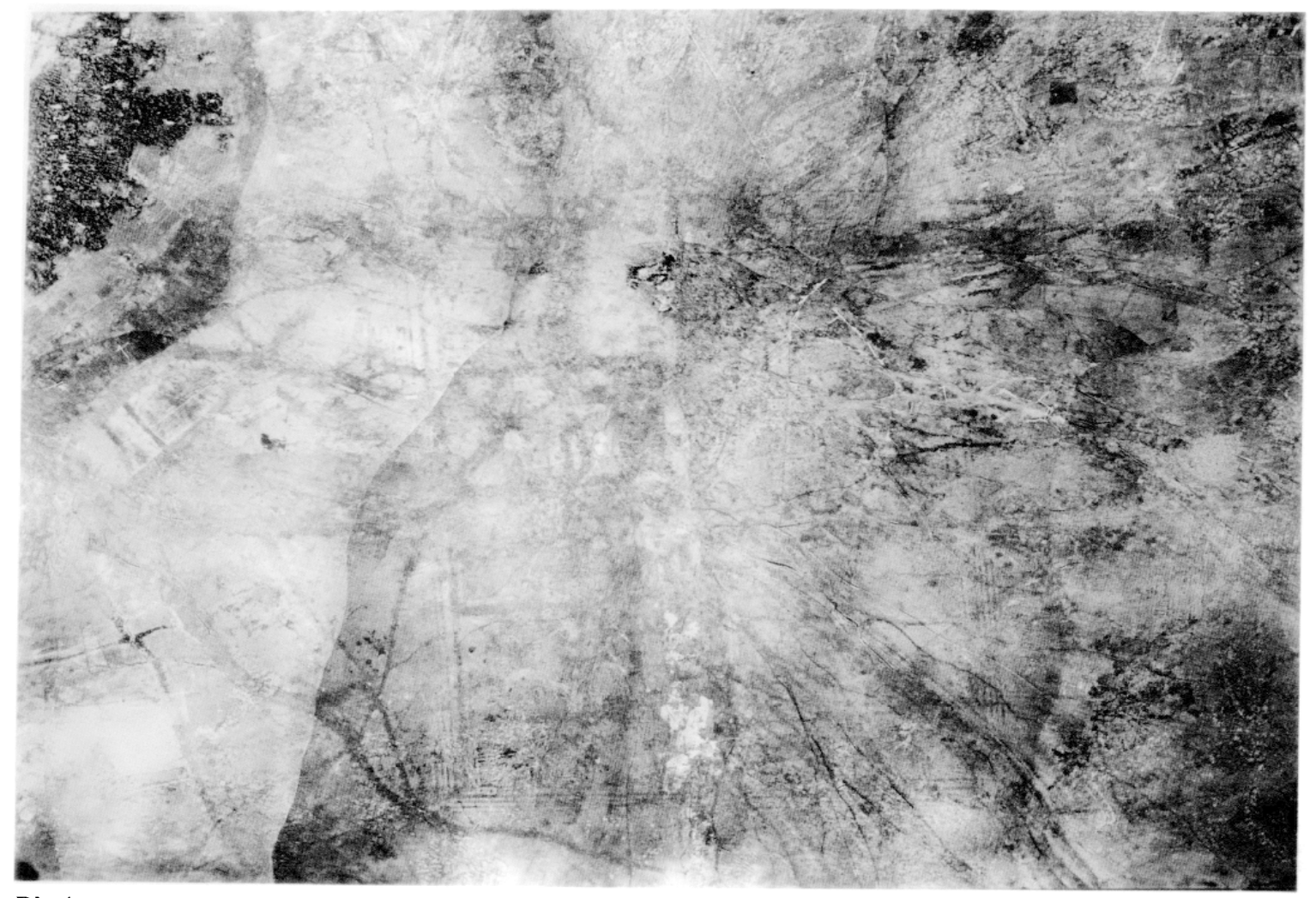

PI. 4

PI. 2. Angle sud-ouest de la ville de ÓC Eo (vue depuis le nord-est). ('liché EFEO) Bernard Philippe Groslier.

PI. 3. Angle sud-ouest de la ville de ÓC Eo (vue depuis le sud-est). (liché FEEO) Bernard Philippe Groslier.

Pl. 4. Vue d'ensemble de la villè de Óc Eo. "Cliché Aéronautique militaire (Cauchetier) " (Malleret 1959-1963, vol. I. planche XI.IX).

PI. 5. Interprétation du plan de Óc Eo par Malleret (Malleret 1959-1963, vol. I. planche XV).

PI. 5
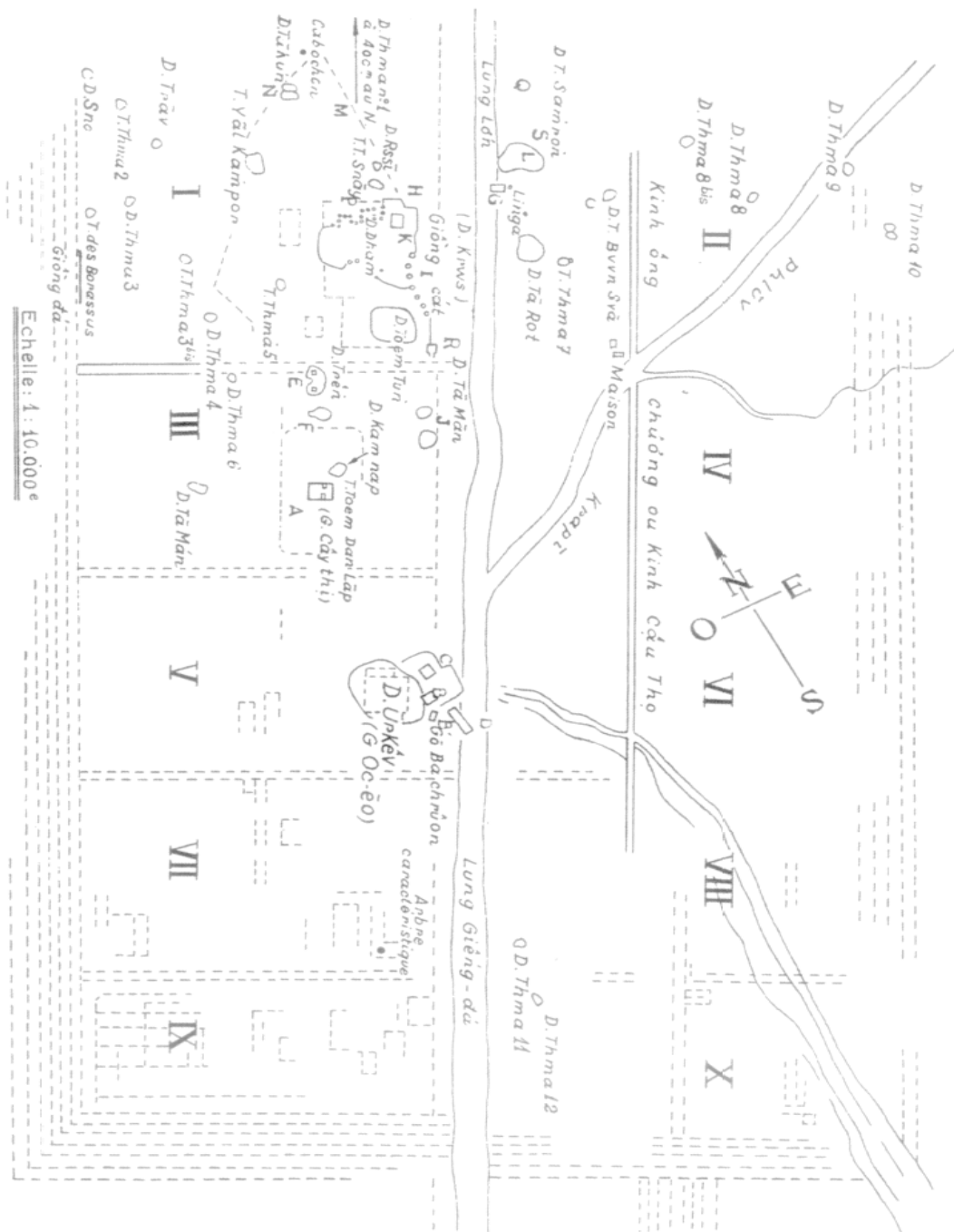

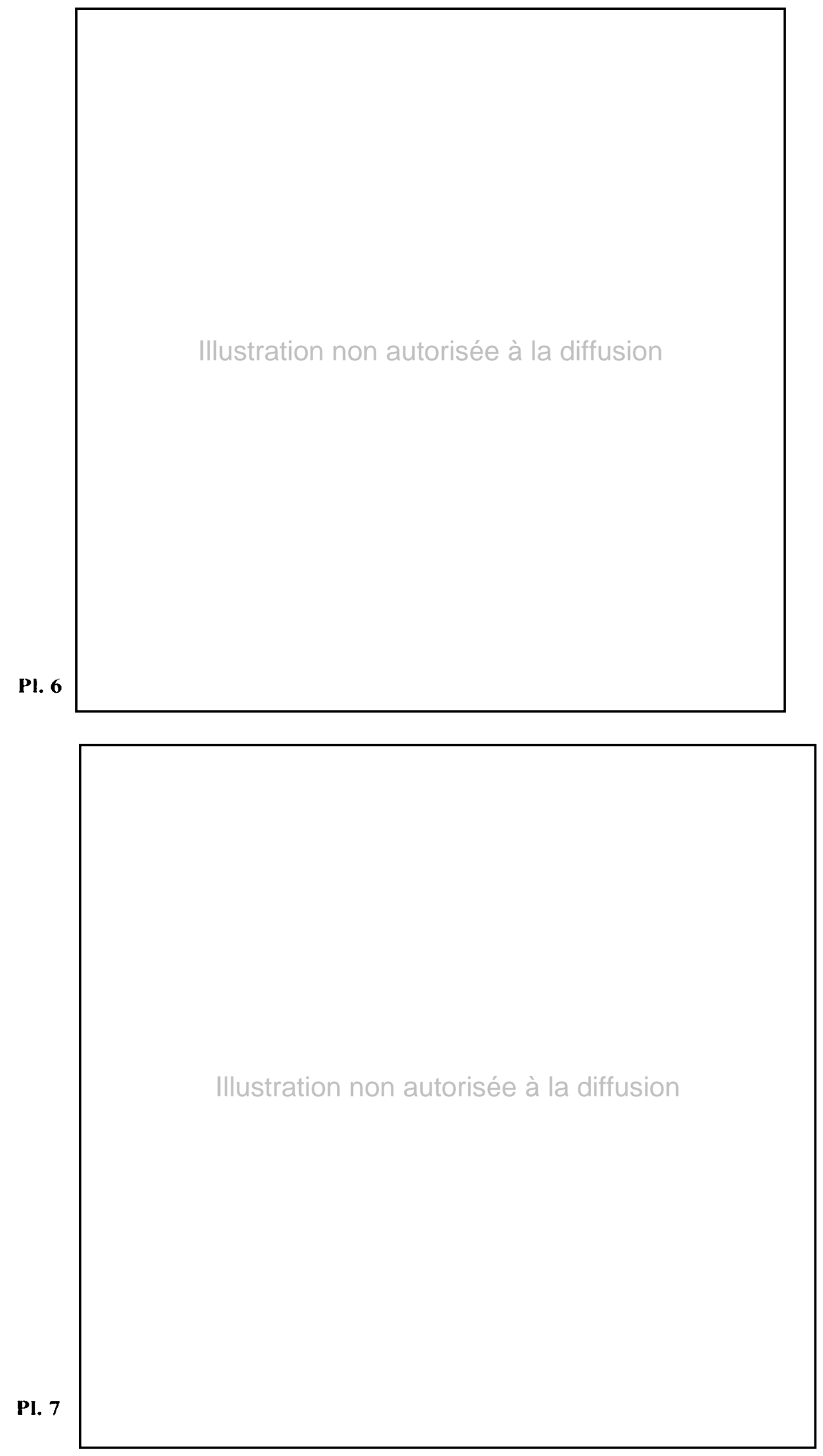


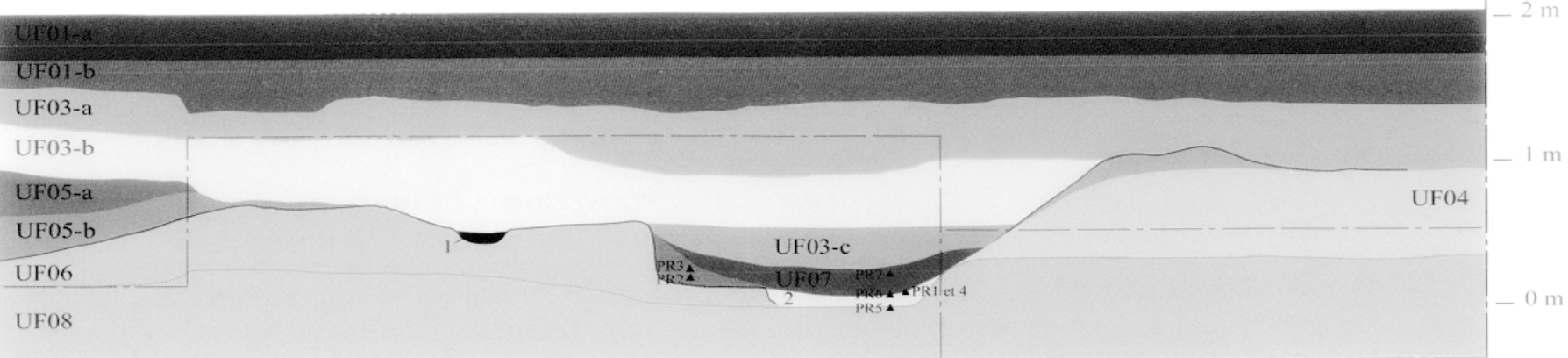

PI. 8

Pl. 6. Relevé du plan « en damier " de Óc Eo d'aprés le cliché de la pl. 4 (réalisation : ('hrin Narong).

PI. 7. Restitution du tracé théorique de la ville de Oc Eo (réalisation : ('hrin Narong).

Pl. 8. Coupe stratigraphique de la douve intérieure de l'enceinte de Ó Eo.

P1. 9. La ville de «Banteay ('hhoeu ). Relevé effectué à partir d images EFEO, SGI (Service géographique de I"Indochine) et Google Earth (réalisation : (hrin Narong). 


\section{Bibliographie}

Anci Chouléan

1990 "La communauté rurale khmère du point de vue du sacré », Journal casiatique 258/1-2, p. 135-154.

AYMONIt:R, Étienne

1900 Le Cambodge. I. Le Rovanme actuel, Paris, Ernest Leroux.

1901 Le Cambodge. II. Les provinces siamoises, Paris, Ernest Leroux.

BiLLıINA, Bérénice

2002 «Le port protohistorique de Khao Sam Kaeo en Thaïlande péninsulaire. Lieu privilégié pour l'étude des premières interactions indiennes et sud-est asiatiques? », BEFEO 89, p. 329-357.

Birqui:, Augustin

1993 Du geste à la cité. Formes urbaines et lien social au Japon, Paris, Gallimard.

BoISSELIFR, Jean

1953 "Les anciennes capitales du Cambodge », Cambodge, revue illustrée khmère 1, p. 17-24.

1965 « Nouvelles données sur l'histoire ancienne de la Thaïlande », Conférence, Alliance française/Centre culturel [Bangkok], 7 pages (sans pagination), introduction par Marie-Jean Vinciguerra.

1992 «1. La signification d'Angkor Thom. 2. Prasat Thom de Koh Ker et Banteay Srei. 3. Oc-èo ", Rencissance culturelle du Cambodge 6, p. 259-284.

BOURIONNI:AU, Éric

2003a «Culturalisme el historiographie du Cambodge ancien : à propos de la hiérarchisation des sources de l'histoire khmère ", Moussons 7, p. 39-70.

$2003 b$ "The Ancient Canal System of the Mekong Delta. Preliminary Report", dans A. K^RLSTROM \& A. Källín (éd.), Fishbones and Glittering Emblems. Southeast Asian Archaeology 2002. Stockholm, Museum of Far Eastern Antiquities, p. 257-270.

Bourdonniau, Éric \& Mangiun, Pierre-Yves

2000 "A new absolute chronology for the 1 st millenium AD in the Mekong Delta ", communication présentée à la 8 "Conférence internationale de l'Association européenne des archéologues sud-est asiatiques (oct. 2000), Sarteano, Italie).

BRALIE:I., Fernand

1973 Capitalism and Material Life, 1400-1800, trad. Miriam Kochan, London, Weidenfeld and Nicolson [éd. française : 1967].

BRONSON, Bennett

1990 «Glass and beads at Khuan Lukpad, Southern Thailand», dans I. \& E. Gı.ovi:R (éd.). Southeast Asian Archaeology 1986, Oxford, BAR (BAR International Series 561), p. 213-230.

Brown, Robert

1992 "Indian art transformed: The earliest sculptural styles of Southeast $\Lambda$ sia " dans lillen M. RAvin \& Karel R. van Koou (éd.), Indian art and archaeology: Leiden \& New York, Brill, p. 41-53. 
(IIMY) I.tR, David

1996 "Songs at the edge of the forest: Perceptions of order in three (ambodian

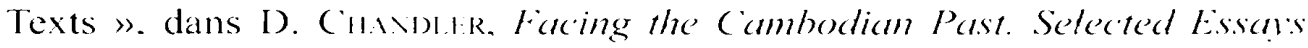
197I-1994. Chiang Mai, Silkworm Books, p. 76-99.

CHARTIIR, Roger

$1998[1989]$ "Le monde comme représentation" (source: Annales E.S.C. 1989. 6), dans R. Charthr, Au bord de la falciise. I histoire entre certitudes et inquićtucke, Paris, Albin Michel, p. 67-86.

C'HRISTH, Anthony H.

1979 "Lin-i. Fu-nan, Java", dans R.B. Smitu \& W. Warson (éd.). Early South East Asiar essal's in archaeologi: history and historical geography. New York \& Kuala Lampur, Oxford University Press, p. 281-287.

C(a)is, George

1942 Inscriptions du Cambodge, Vol. 2, Hanoi, EFEO.

1943-1946 «Études cambodgiennes XXXVI: Quelques précisions sur la fin du Fou-Nan »,BEFEO 43, p. 1-8.

1964 [1948] Les États hindouisés d'Indochine et d'Indonésie. Paris, de Boccard.

Cor: Michael D.

1957 «The Khmer Settlement Pattern: A Possible Analogy with That of Maya », American Antiquit. 22/4, p. 409-410.

Darifns, Bruno

1994 "Le temple indien en Asie du Sud-Est. Archéologie d'une forme », dans F. Bl\%or (dir.), Recherches nouvelles sur le Cambodge, Paris, EFFO, p. 259272.

DALshimimer, Nadine

1998 "La statuaire khmère et ses rapports avec les pays extérieurs au cours de l'histoire. L'exemple de l'influence indonésienne ", dans La Khmérologie. Connaissance du passé et contribution au renouveau du Cambodge. Proceedings of International Conference on Khmer Studies, Phnom Penh. 26-30 August 1996, vol. 1, Phnom Penh, Sorn Samnang, p. 487- 503.

Di: Cholsy, François-Timoléon

2006 Journal du Voyage de Siam, fait en 1685 et 1686 par M. L'Abbé de Choisy, Genève, Olizane [1 ${ }^{\text {re éd. }}$ 1687].

Delvirit, Jean

1994 Le pavsan cambodgien, Paris, L'Harmattan.

DETHENN:, Marcel

2000 Comparer l'incomparable, Paris, Seuil.

DLMONT, Louis

1979 "Postface à l'édition "Tel": Vers une théorie de la hiérarchie », dans

L. Dumont. Homo Hierarchicus. Le sistème des castes et ses implications, p. 396-403.

DUPONT, Florence

2005 "L'altérité incluse. L'identité romaine dans sa relation à la (jrèce ", dans F. Dupont \& E. Valittr-Cacinac (dir.). Façons de parler gree à Rome. Paris. Belin. p. 255-277. 
Dupont, Pierre

1955 La statuaire préangkorienne, Ascona, Artibus Asiae (Supplementum XV).

FI:RLuS, Michel

2005 "L'intérêt linguistique des transcriptions chinoises concernant le Cambodge ancien (Fou-nan et Tchen-la) », communication présentée aux $19^{\circ}$ journées de linguistique de l'Asie orientale, CRLAO (EHESS-CNRS), 12 p.

Fori:st, Alain

1992 Le culte des génies protecteurs an Cambodge. Analyse et traduction d'un corpus de textes sur les neak ta, Paris, L'Harmattan.

Fox, E. W.

1971 History in Geographic Perspective, New York, Norton.

GAUCHER, Jacques

2003 «Premiers aperçus sur des éléments de planification urbaine à Angkor Thom ", Udaya 4, p. 41-52.

2004 «Angkor Thom, une utopie réalisée? Structuration de l'espace et modèle indien d'urbanisme dans le Cambodge ancien ", Arts asiatiques 59/2, p. 5886.

Greater Angkor Project

2003 « Redefining Angkor: structure and environment in the largest low density urban complex of the pre-industrial world », Udana 4, p. 107-125.

Griswol.D, Alexander B.

1966 "Imported images and the nature of copying in the art of Siam», dans Essans offered to G. H. Luce, 2 vol., Ascona, Artibus Asiae Publishers, p. 37-73.

Grosi.ll:k, Bernard Philippe

1961 Indochine. Carrefour des Arts, Paris, Albin Michel (coll. "L'Art dans le monde, fondements historiques, sociologiques et religieux $»)$.

1973 «Pour une géographie historique du Cambodge », Les Cahiers d'outre-mer 104, p. 337-379.

1974 «Agriculture et religion dans l'empire angkorien », Études Rurales 53-5455-56, p. 95-117.

1979 «La cité hydraulique angkorienne : exploitation ou surexploitation du sol?", BEFEO 66, p. 161-202.

1985 "Archéologie des échanges commerciaux", dans Le Grand Atlas de l'Archéologie, Paris, Encyclopadia Universalis, p. 254-255.

HıilHAM, Charles

2002 Early cultures of Mainland Southeast Asia, Bangkok, River Books.

IstrizawA Yoshiaki, JAcQuis, Claude \& Kinn Sok

2007 Manuel d'épigraphic du Cambodge (avec la collaboration de Uraisi Varasarin, Michael Vickery, Tatsuro Yamamoto), Paris, EFEO \& UNESCO.

JACQ-Hi:R(iouni.'H, Michel

1990 "Le monde malais et le monde indochinois : relations artistiques », dans Le moncle inclochinois er la péninsule malaisé. Contributions de la Délégation française au deuxième congrès international sur la civilisation malaise organisé par le ministère de la Culture et du Tourisme de Malaisie, Kuala Lumpur, p. 115-139. 
Jacots. Claude

1986 «L Le pays khmer avant Angkor». Journal des scrumts (janv.-sept.. p. 59-95).

Jucols. (laude \& Philippe Lavox)

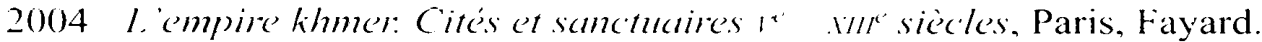

KIRHI., W.

1920 Die Kosmographie der Inder: nach den Quellen dargestellt, Bonn \& Leipzig. Kurt Schroeder.

LII BSTRMAN, Victor

2003 Strange Parallels: Southeast Asia in Global Context, c. 800)-1830, Vol. 1 : Integration on the Mainland. C ambridge. Cambridge University Press.

L.(MIIB.IRD. Denys

1970 "Pour une histoire des villes du Sud-Est Asiatique ". Annales, ESC 4, p. 842856.

1990) Le carrefon javanais. Essai d'histoire globale, t. I : Les limites de loccidentalisation, t. II : Lès réseanx asiatiques, t. III : L'héritage des rovames concentrique's, Paris, École des hautes études en sciences sociales.

1994 "À propos de l'histoire des villes d'Asie du Sud-Est. Nouvelles considérations ". Cahiers de la recherche architecturale 35-36 (Cités d'Asie), p. 99-106.

Lico, Fabienne

1998 "Pratiques et représentations de l'espace d'un village du site d'Angkor: Srah Srang cheung ". dans Actes du Congrès national de la recherche socioculturelle sur le Cambodge (Phnom Penh. 17-19 déc. 1997), université de Phnom Penh, p. 181-192.

MaK Phœun

1991 "Le phénomène urbain dans le Cambodge post-angkorien", dans Péninsule indochinoise. Études Liraines, Paris, L’Harmattan, p. 39-57.

MALLFRET, Louis

1959-1963 L'archéologie du delta du Mékong. 4 vol., Paris, EFEO (PEFEO 43).

Mancilis, Pierre-Yves

2002 Rapport préliminaire, campagne 2002 (Rapport de la Mission Archéologie du delta du Mékong adressé à la Commission consultative des Recherches archéologiques françaises à l'étranger), École française d'Extrême-Orient. (non publié).

Miksic, John N.

2000 «Heterogenetic Cities in Premodern Southeast Asia », World Archueology $32 / 1$, p. $106-120$.

NÉPOT:, Jacques

1992 Parenté et organisation sociale dans le Cambodge moderne et contemporain. Quelques aspects et quelques applications du modèle les régissant, Genève, Olizane.

2003 «Comprendre la maison cambodgienne ", Péninsule 47, p. 93-156.

2004 "Comprendre la maison cambodgienne (II). Troisième et dernière partie : à la recherche du sens ", Péninsule 49, p. 5-95. 
Nípote, Jacques \& Sisowath, R. Monipong

1994 État présent de la Maison Rovale du Cambodge, Paris, Institut de la Maison Royale du Cambodge.

O'CONNOR Jr, Stanley J.

1972 Hindus Gods of Peninsular Siam, Ascona, Artibus Asiae Publishers.

O'CONNOR, Richard

1995 "Indigenous Urbanism: Class, City and Society in Southeast Asia », JSEAS, $26 / 1$, p. $30-45$.

OVI:SI:N Jan, TRANKILLL Ing-Britt \& Joakim ÖJINIDAL.

1996 When Every Household is an Island. Social Organisation and Power Structures in Rural Cambodia, Uppsala, Uppsala University (Uppsala Research Reports in Cultural Anthropology 15).

PARIS, Pierre

1941 « L'importance rituelle du Nord-Est et ses applications en Indochine ", BEFEO 41, p. 303-334.

Parmentif:R, Henti

1927 L'art khmèr primitif, 2 vol., Paris, EFEO (PEFEO 21-22).

PlitLlot, Paul

1903 "Le Fou-nan ", BEFEO 3, p. 248-303.

1925 "Quelques textes chinois concernant l'Indochine hindouisée », dans Études asiatiques, publiées à l'occasion du vingt-cinquième anniversaire de l'École ficançaise d'Extrême-Orient, vol. II, Paris, EFEO, p. 243-263.

1951 [1997] (CEuvres posthumes), Mémoires sur les coutumes du Cambodge de Trheou Ta-Koucm, Paris, Adrien Maisonneuve.

PI:RRIT, Danicl

1999 «La cité royale dans la littérature traditionnelle malaise : représentation et contribution à l'histoire des cités anciennes du monde malais », Aséanie 3, p. 75-89.

Pollock, Sheldon

2007 Sanskrit, Culture and Power in the Premodern India, New Delhi, Permanent Black.

Porit:-Maspitro, Eveline

1962-1969 Étude sur les rites agraires des Cambodgiens, 3 vol., Paris, Mouton.

PORTF, Bertrand

2003 "Nouveau regard sur sept sculptures exposées dans la galerie sud du Musée National de Phnom Penh », Udạa 4, p. 83-87.

PoTtil: Christophe

1999 "Carte archéologique de la Région d’Angkor Zone Sud », 3 vol., thèse de doctorat, université Paris III - Sorbonne Nouvelle.

2000a "À la recherche de Goloupura », BEFEO 87/1, p. 79-107.

$2000 \mathrm{~b}$ " Some evidence of an inter-relationship between hydraulic features and rice field patterns at Angkor during ancient times », Journal of Asicun Studies 18, p. 99-120.

2002 "Perspectives de la mission archéologique franco-khmère sur l'aménagement du territoire angkorien ". Udanca 2, p. 117-132. 
Rar. Ilimanshu Prabha

1991 «In search of Suvarnabhumi: Larly sailing networks in the Bay of Bengal ".

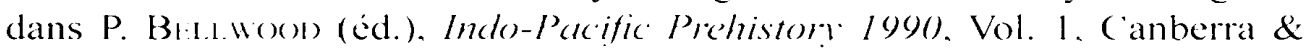
Jakarta, Indo-Pacific Prehistory Association, p. 357-365.

1994 The Winds of Change. Buddhism and the Maritime Links of Early South Asia, Dehli, Oxford University Press.

RIIDFIII.D. R. \& R. SivilitR

1954 "The cultural role of cities ". Economic Development and Social Change 3, p. $335-373$.

R(:ID, Anthony

1980 "The structure of cities in Southeast Asia: fifteenth to seventeenth centuries", Journal of Southeast Asian Studies 11/2, p. 235-250.

1988 Southeast Asia in the Age of (ommere. 1450-1680) vol. 1: The lands below the Winds, New Haven \& London, Yale University Press.

1993 Southeast Asia in the Age of Commere. 1450-1680, vol. 2 : Expansion and (risis. New Haven \& London. Yale University Press.

RI: vol. Louis

1985 |1947] "Les formes religieuses ", dans L. Ri:Nol et J. Fil.II)/AT (avec le concours de P. Meile, A.-M. Esnoul et L. Silburn), L'Inde classique. Manuel des études indienne's, t. I, Paris. Maisonneuve, p. 480-620.

TAINTt RIIR. François (éd.)

2006 Wooden Architecture of Cambodia. A Disappearing Heritage. Phnom Penh. Center for Khmer Studies.

Thaply.s., Kiran Kumar

1996 (iutlds in Ancient India. A Study of Guild Organization in Northern India and Western Deccan from circa 600$) B($ to circa 600 . AI). New Dehli, New Age International.

THIERRY, Solange

1985 Le C'ambodge des contes, Paris, L'Harmattan.

VICKI:RY, Michael

1998 Society: Economics and Politics in Pre-Angkor Cambodici. The 7th-8th Centuries, Tokyo, The Toyo Bunko, Centre for East Asian Cultural Studies for Unesco.

2003-04 «Funan Reviewed : Deconstructing the Ancients », BEFEO 90-91, p. $101-143$.

Vo Si KIIAI

2003 "The Kingdom of Funan and the Culture of Oc Eo ». dans James C. M. Kilo) (éd.), Art \& Archaeology of Fu Nan: Pre-Khmer Kingdom of the Lower Mekong Valley, Bangkok, The Southeast Asian Ceramic Society, Orchid Press, p. 35-85.

Whithis, Paul

1961 The Golden Khersonese: Studies in the historical geography of the Malay. Peninsula before A.D. 1500). Kuala Lumpur. Oxford University Press.

1983 . Vagara and Commandery: Origins of the Southeast Asian urhan traditions, ('hicago. University of Chicago, Department of Geography (Research Paper 207-208). 
Wisseman Cirristie, Jan

1995 «State formation in Early Maritime Southeast Asia: A consideration of the theories and the data », Bijdragen tot de Taal-, Land-en Volkenkunde, 151/2, p. 235-288.

1998 "Javanese Markets and the Asian Sea Trade Boom of the Tenth to Thirteenth Centuries A.D. ", Journal of the Economic and Social History of the Orient 4l-3, p. 344-381.

1999 "Asian Sea Trade between the Tenth and Thirteenth Centuries and Its Impact on the States of Java and Bali » dans H. P. RAY (éd.), Archcieology of Seafaring, p. 221-270.

WorTIRS, Oliver W.

1999 History, Culture, and Region in Southeast Asian Perspectives, $2^{\circ}$ éd. rév., Ithaca (New York), Cornell University Press, Southeast Asia Program Publications, [1 ${ }^{\text {re }}$ éd. 1982]. 